NBER WORKING PAPER SERIES

\title{
ARE HIGH-INTEREST LOANS PREDATORY? THEORY AND EVIDENCE FROM PAYDAY LENDING
}

\author{
Hunt Allcott \\ Joshua J. Kim \\ Dmitry Taubinsky \\ Jonathan Zinman \\ Working Paper 28799 \\ http://www.nber.org/papers/w28799
NATIONAL BUREAU OF ECONOMIC RESEARCH
1050 Massachusetts Avenue
Cambridge, MA 02138
May 2021

We thank Xavier Gabaix, David Laibson, Adair Morse, Manisha Padi, Paige Skiba, Jeremy Tobacman, and seminar participants at Berkeley, the California Department of Financial Protection and Innovation, the CFPB Research Conference, Cornerstone Research, Harvard, Harvard Business School, the IPA Financial Inclusion Conference, the London School of Economics, NBER Public Economics Meeting, Northwestern, Opportunity Insights, Stanford, Stanford Institute for Theoretical Economics, Stockholm University, the UK Financial Conduct Authority, University of Copenhagen, and Uppsala for helpful feedback. We thank the Sloan Foundation for grant funding. We are grateful to Raj Bhargava, Surya Ierokomos, Eric Koepcke, and Afras Sial for outstanding research assistance, to Melissa Horste and Innovations for Poverty Action for dedicated project management, and to employees of the partner payday lender for their collaboration on the project. Our Memorandum of Understanding with the lender allowed us to publish this research without prior review by the lender and granted zero editorial control to the lender. The experiment was registered in the American Economic Association Registry for randomized trials (trial ID AEARCTR-0003043, available from www.socialscienceregistry.org/trials/3043) and was approved by Institutional Review Boards at NYU (protocol number FY2018-1997), Stanford (\#46136), and IPA (\#14663). The views expressed herein are those of the authors and do not necessarily reflect the views of the National Bureau of Economic Research.

NBER working papers are circulated for discussion and comment purposes. They have not been peer-reviewed or been subject to the review by the NBER Board of Directors that accompanies official NBER publications.

(C) 2021 by Hunt Allcott, Joshua J. Kim, Dmitry Taubinsky, and Jonathan Zinman. All rights reserved. Short sections of text, not to exceed two paragraphs, may be quoted without explicit permission provided that full credit, including $\odot$ notice, is given to the source. 
Are High-Interest Loans Predatory? Theory and Evidence from Payday Lending

Hunt Allcott, Joshua J. Kim, Dmitry Taubinsky, and Jonathan Zinman

NBER Working Paper No. 28799

May 2021

JEL No. D14,D15,D18,D61,D90,L69

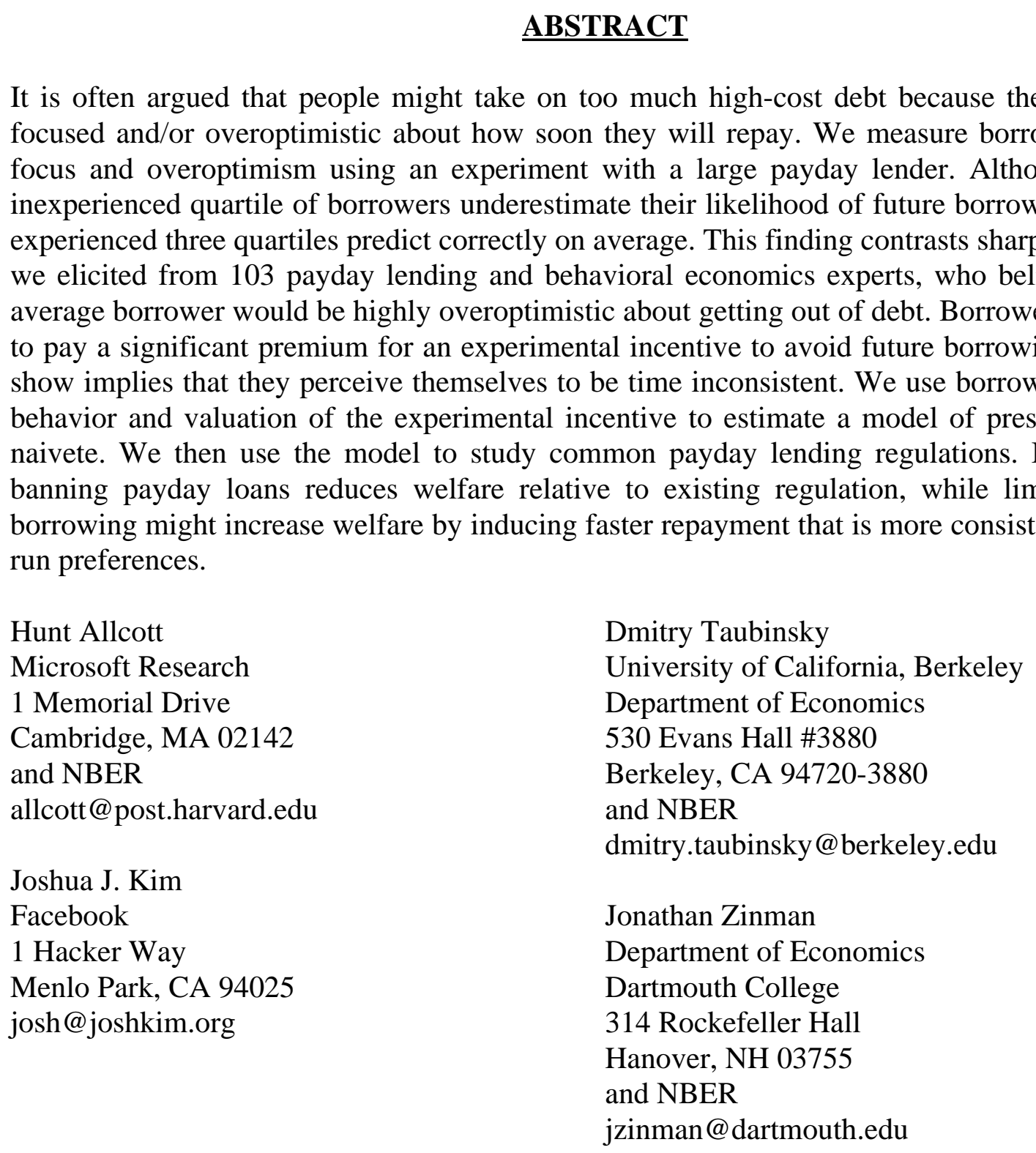

An online appendix and replication files is available at http://www.nber.org/data-appendix/w28799 
"The most hated sort [of wealth-getting], and with the greatest reason, is usury, which makes a gain out of money itself, and not from the natural object of it."

-Aristotle (Politics)

"No man of ripe years and of sound mind, acting freely, and with his eyes open, ought to be hindered ... in the way of obtaining money, as he thinks fit."

-Jeremy Bentham (Defense of Usury, Letter 1, 1787)

\section{INTRODUCTION}

People have long questioned the ethics and social consequences of high-interest lending. Indeed, usury laws and other high-interest lending restrictions are among the oldest and most common forms of consumer protection regulation. However, the extent to which such regulation actually benefits or harms consumers is still poorly understood, as it depends on the extent to which consumers are acting in their own best interest. In this paper, we use an experiment to study two key hypothesized behavioral biases of payday loan borrowers in the United States.

Critics argue that payday loans are predatory, trapping consumers in cycles of repeated highinterest borrowing. A typical payday loan incurs $\$ 15$ interest per $\$ 100$ borrowed over two weeks, implying an annual percentage rate (APR) of 391 percent, and more than 80 percent of payday loans nationwide in 2011-2012 were reborrowed within 30 days (CFPB 2016). As a result of these concerns, 18 states now effectively ban payday lending (CFA 2019), and in 2017, the Consumer Financial Protection Bureau (CFPB) finalized a set of nationwide regulations. The CFPB's thendirector argued that "the CFPB's new rule puts a stop to the payday debt traps that have plagued communities across the country. Too often, borrowers who need quick cash end up trapped in loans they can't afford" (CFPB 2017).

Proponents argue that payday loans serve a critical need: people are willing to pay high interest rates because they very much need credit. For example, Knight (2017) wrote that the CFPB regulation "will significantly reduce consumers' access to credit at the exact moments they need it most." Under new leadership, the CFPB rescinded part of its 2017 regulation on the grounds that it would reduce credit access.

At the core of this debate is the question of whether borrowers act in their own best interest. If borrowers successfully maximize their utility, then restricting choice reduces welfare. However, if borrowers have self-control problems ("present focus," in the language of Ericson and Laibson 2019), then they may borrow more to finance present consumption than they would like to in the long run. Furthermore, if borrowers are "naive" about their present focus, overoptimistic about their future financial situation, or for some other reason do not anticipate their high likelihood of repeat borrowing, they could underestimate the costs of repaying a loan. In this case, restricting credit access might make borrowers better off.

We designed and implemented an experiment with a large payday lender (henceforth, the "Lender") to answer two key questions. First, do borrowers anticipate the extent of their re- 
peat borrowing? Second, do borrowers perceive themselves to be time consistent? Our experiment provides model-free evidence on these questions and also identifies a structural model of present focus with partially naive beliefs - one of the first such estimates outside of laboratory experiments. We then use our structural estimates as inputs to welfare analysis of three common payday lending regulations - the first such analysis that accounts for key potential behavioral biases motivating these regulations.

Our experiment ran from January to March 2019 in 41 of the Lender's storefronts in Indiana, a state with fairly standard lending regulations. Customers taking out payday loans were asked to complete a survey on an iPad. The survey first elicited people's predicted probability of getting another payday loan from any lender over the next eight weeks. We then introduced two different rewards: "\$100 If You Are Debt-Free," a no-borrowing incentive that they would receive in about 12 weeks only if they did not borrow from any payday lender over the next eight weeks, and "Money for Sure," a certain cash payment that they would receive in about 12 weeks. We measured participants' valuations of the no-borrowing incentive through an incentive-compatible adaptive multiple price list (MPL) in which they chose between the incentive and varying amounts of Money for Sure. We also used a second incentivized MPL between "Money for Sure" and a lottery to measure risk aversion. The 1,205 borrowers with valid survey responses were randomized to receive either the no-borrowing incentive, their choice on a randomly selected MPL question, or no reward (the Control group). We match each participant's survey responses to borrowing data from the Lender and to the state-wide database of borrowing from all payday lenders.

We first provide model-free results on the two key questions above. On the first question, we find that on average, people almost fully anticipate their high likelihood of repeat borrowing. The average borrower perceives a 70 percent probability of borrowing in the next eight weeks without the incentive, only slightly lower than the Control group's actual borrowing probability of 74 percent. Experience matters. People who had taken out three or fewer loans from the Lender in the six months before the survey - approximately the bottom experience quartile in our sample - underestimate their future borrowing probability by 20 percentage points. By contrast, more experienced borrowers predict correctly on average. This contrasts with findings of substantial average naivete in lab experiments (Augenblick and Rabin 2019) and exercise (e.g., DellaVigna and Malmendier 2004; Acland and Levy 2015; Carrera et al. 2021). A potential explanation for this difference is that payday borrowing is a high-stakes decision with clear feedback and repeated opportunities to learn.

To answer the second key question, we adapt the Carrera et al. (2021) test for perceived time inconsistency. The $\$ 100$ If You Are Debt-Free incentive is equivalent to a $\$ 100$ certain payment plus a $\$ 100$ increase in the price of re-borrowing. Thus, risk-neutral and time-consistent borrowers would value the incentive at $\$ 100$ minus the consumer surplus loss from a $\$ 100$ price increase. For example, consider risk-neutral and time-consistent people who predict that the incentive would reduce their borrowing probability from 70 percent to 50 percent. If demand is approximately linear, the consumer surplus loss from the price increase is the trapezoid under their demand curve as a 
$\$ 100$ price increase reduces demand from 70 to 50 percent: $\$ 100 \times(70 \%+50 \%) / 2=\$ 60$. Thus, they would be indifferent between the incentive and a fixed payment of approximately $\$ 100-\$ 60=\$ 40$. Since the incentive is risky, risk aversion would reduce that valuation below $\$ 40$. Time-inconsistent borrowers who believe that their future selves will borrow more than their current preferences would have higher valuations, because the incentive reduces future borrowing, in line with current preferences. Thus, if these example borrowers value the incentive at more than $\$ 40$ and are also risk averse, we infer that they perceive themselves to be time inconsistent.

On average, borrowers value the no-borrowing incentive 30 percent more than they would if they were time consistent and risk neutral. And since their valuations of our survey lottery reveal that they are in fact risk averse, their valuation of the future borrowing reduction induced by the incentive is even larger than this 30 percent "premium" suggests. Qualitative data support the inference that borrowers want to change their behavior: 54 percent of our sample reports that they "very much" would like to give themselves extra motivation to avoid payday loan debt in the future, and only 10 percent report "not at all."

We use these model-free results to help identify a structural model of partially naive present focus. Specifically, we assume that people have quasi-hyperbolic time preferences (e.g., Laibson, 1997; O'Donoghue and Rabin, 1999), meaning that utility in all future periods is discounted by an additional $\beta \leq 1$. We follow O'Donoghue and Rabin (2001) in allowing people to mispredict their present focus, believing that their future selves will discount later periods by $\tilde{\beta}$. "Sophisticated" people have $\tilde{\beta}=\beta$, and "naive" or "partially naive" people have $\tilde{\beta}>\beta$.

Borrowers' predicted versus actual borrowing probabilities identify sophistication versus naivete. The small degree of average misprediction in our data translates to an average value of $\beta / \tilde{\beta}$ that ranges from 0.95 to 0.98 , depending on risk aversion assumptions. The least experienced quartile of borrowers have $\beta / \tilde{\beta}$ between 0.79 and 0.89 . Borrowers' valuations of the no-borrowing incentive identify average perceived present focus $\tilde{\beta}$. The large observed premium translates to average $\tilde{\beta}$ between 0.76 and 0.87 , implying that borrowers believe they have significant self-control problems. Combining our estimates of $\beta / \tilde{\beta}$ and $\tilde{\beta}$ implies an average $\beta$ between 0.74 and 0.83 .

At the end of the paper, we discuss potential policy implications of these results. We ground our discussion in a simple model of borrowing and repayment that builds on Heidhues and Koszegi (2010). Borrowers first choose a loan amount in period 0. In each subsequent period, borrowers receive a stochastic repayment cost shock and can choose to repay the loan, reborrow, or default. Allowing for stochastic cost shocks is crucial, as it implies that behavior, and thus welfare, is continuous in the level of naivete. Prior work in deterministic models has found that even small amounts of naivete can cause discontinuously large effects on behavior and thus large welfare losses (O’Donoghue and Rabin 1999, 2001; Heidhues and Koszegi 2009, 2010). But in our nondeterministic model, large welfare losses obtain only with large and peristent naivete - and as discussed above, we do not see any persistent naivete in our data. We further show that losses from naivete can be bounded using observed behavior, and simple calibrations suggest that these losses are small in our setting. 
We calibrate the model with our estimates of $\beta$ and $\tilde{\beta}$ and simulate the welfare effects of common payday lending regulations. We find that under a standard $\$ 500$ loan size cap, borrowers with our estimated $\beta$ and $\tilde{\beta}$ enjoy 89 to 96 percent as much surplus as a time-consistent borrower. Because borrowers are close to fully sophisticated about repayment costs, payday loan bans and tighter loan size caps reduce welfare in our model. Limits on repeat borrowing increase welfare in some (but not all) specifications, by inducing faster repayment that is more consistent with long-run preferences. In our model, these conclusions are robust to various assumptions about learning and heterogeneity in present focus and naivete. Of course, we do not know if our conclusions would be robust to all possible alternative models and parameter assumptions, and we highlight six important caveats in Section 8.4.

Before we released the paper, we surveyed academics and non-academics who are knowledgeable about payday lending to elicit their policy views and predictions of our empirical results. We use the 103 responses as a rough measure of "expert" opinion, with the caveat that other experts not in our survey might have different views. The average expert did not correctly predict our main results. For example, the average expert predicted that borrowers would underestimate future borrowing probability by 30 percentage points, which would imply much more naivete than our actual estimate of 4 percentage points.

Section 2 discusses related literature. Sections 3-6 present the background, experimental design, data, and reduced-form empirical results. Section 7 presents the present focus model and estimation, Section 8 considers welfare and policy implications, and Section 9 concludes.

\section{RELATED LITERATURE}

Our work builds on several existing literatures. One literature uses quasi-experimental variation to evaluate the impacts of payday loan access (Zinman 2010; Melzer 2011, 2018; Morse 2011; Morgan, Strain, and Seblani 2012; Carrell and Zinman 2014; Bhutta, Skiba, and Tobacman 2015; Bhutta, Goldin, and Homonoff 2016; Carter and Skimmyhorn 2017; Gathergood, Guttman-Kenney, and Hunt 2019; Skiba and Tobacman 2019). These papers consider a variety of different outcomes and find a mix of positive and negative effects. Such impact evaluations cannot be used for welfare analysis because it is not clear how to trade off effects on different outcomes, how to consider other unmeasured welfare-relevant outcomes, or how to evaluate regulations such as rollover restrictions that change the payday loan product instead of eliminating access. This highlights the need for welfare analyses that include explicit measures of consumer bias. Our paper is the first to do this for payday lending, thus situating questions about regulation of payday borrowing in the Behavioral Public Economics literature (see Bernheim and Taubinsky, 2018, for a review). ${ }^{1}$

We also build on existing papers studying imperfect information and behavioral biases among

\footnotetext{
${ }^{1}$ For other examples of this approach to behavioral policy evaluation, see Chetty, Looney, and Kroft (2009), Abaluck and Gruber (2011), Handel (2013), Allcott and Taubinsky (2015), Bronnenberg et al. (2015), Grubb and Osborne (2015), Handel and Kolstad (2015), Taubinsky and Rees-Jones (2018), Allcott, Lockwood, and Taubinsky (2019), Handel, Kolstad, and Spinnewijn (2019), and Rees-Jones and Taubinsky (Forthcoming).
} 
payday loan borrowers. Bertrand and Morse (2011) show that providing information to first-time borrowers about fees and the likelihood of repeat borrowing reduces borrowing. This result is consistent with our finding of naivete among inexperienced borrowers, as the information could induce sophistication and reduce borrowing. ${ }^{2}$ Mann (2013) asks borrowers how long they think it will be before they go an entire pay period without borrowing, finding that 60 percent of borrowers predict correctly within three days. However, Mann (2013) does not present formal statistical tests of whether borrowers are biased on average, and his sample includes only people who have not borrowed in the last 30 days, which may limit the generalizability of his results. Leary and Wang (2016) show that one reason for payday borrowing is a failure to plan for predictable income shocks. Carter et al. (2019) find that payday borrowers who are quasi-experimentally granted more time to repay loans do not repay more, and they show that this is consistent with a model of present focus. Carvalho, Olafsson, and Silverman (2019) show that laboratory measures of decision quality are negatively correlated with high-interest borrowing in Iceland. Relative to these papers, a key contribution of our work is a theoretically driven design that allows us to estimate a model of borrowing behavior, which then allows us to carry out a quantitative behavioral welfare analysis.

Skiba and Tobacman (2018) use observational data on payday borrowing to estimate a present focus model. Their identification exploits the timing of default: in their model, naivete is required to explain long borrowing spells ending in default, as sophisticates would default earlier to avoid the interest payments. However, recent work by Heidhues and Strack (forthcoming), shows that the timing of choices cannot be used to identify either $\beta$ or $\tilde{\beta}$ without additional parametric assumptions, as every distribution of stopping times can be rationalized by a time-consistent model with a different distribution of unobserved shocks. For example, with a right-skewed distribution of income shocks, one might reborrow repeatedly in hopes of repaying upon a high income draw and then default if that high draw doesn't materialize.

Finally, we advance the large empirical literature estimating models of limited self control. Many lab and field experiments attempt to provide evidence for present focus through dynamic preference reversals, demand for commitment, overoptimism, but without estimating model parameters. ${ }^{3}$ Another set of experiments and field studies estimate part of a present focus model, for example identifying $\beta$ while assuming that people are fully naive or fully sophisticated. ${ }^{4}$ There are only a handful of papers that estimate a full model of partially naive present focus. ${ }^{5}$ There also potentially important advantages to our identification strategy, as recent work suggests that

\footnotetext{
${ }^{2}$ Burke, Leary, and Wang (2016) show that this information provision had material effects when implemented throughout Texas.

${ }^{3}$ See, for example, Read and van Leeuwen (1998), Shapiro (2005), Ashraf, Karlan, and Yin (2006), DellaVigna and Malmendier (2006), Gine, Karlan, and Zinman (2010), Duflo, Kremer, and Robinson (2011), Beshears et al. (2015), Goda et al. (2015),Kaur, Kremer, and Mullainathan (2015), Royer, Stehr, and Sydnor (2015), Kuchler and Pagel (2018), Toussaert (2018), Schilbach (2019), John (forthcoming), and Sadoff, Samek, and Sprenger (forthcoming).

${ }^{4}$ See, for example, Fang and Silverman (2004), Shui and Ausubel (2005), Paserman (2008), Acland and Levy (2012), Andreoni and Sprenger (2012a; 2012b), Augenblick, Niederle, and Sprenger (2015), Laibson et al. (2015), Augenblick (2018), Martinez, Meier, and Sprenger (2020), Mahajan, Michel, and Tarozzi (2020).

${ }^{5}$ To our knowledge, these are Allcott, Gentzkow, and Song (2021), Bai et al. (2018), Augenblick and Rabin (2019), Skiba and Tobacman (2018), Chaloupka, Levy, and White (2019), and Carrera et al. (2021).
} 
reported results on preference reversals, commitment contract take-up, and procrastination are not necessarily identifying present focus (see Strack and Taubinsky, 2021, Carrera et al., 2021, Heidhues and Strack, forthcoming, respectively).

Our strategy for identifying present focus parameters adapts the strategy of Carrera et al. (2021), who study moderate incentives for exercise assuming quasilinearity in money and separability of payoffs across periods. ${ }^{6}$ Our more complex empirical setting requires us to extend the strategy to allow for income effects and non-separable dynamics.

\section{PAYDAY LENDING BACKGROUND}

Payday loans are small, high-interest, single-payment consumer loans that typically come due on the borrower's next pay date. In the Lender's data, typical loan maturities are about 14 days for people on weekly, biweekly, or semimonthly pay cycles, and about 30 days for people on monthly pay cycles. In 2016, Americans borrowed $\$ 35$ billion from storefront and online payday lenders, paying $\$ 6$ billion in interest and fees (Wilson and Wolkowitz 2017). In Indiana, the site of our experiment, lenders disbursed 1.2 million payday loans for a total of $\$ 430$ million in 2017 (Evans 2019).

Indiana law caps loan sizes at $\$ 605$ and caps the marginal interest and fees at 15 percent of the loan amount for loans up to $\$ 250,13$ percent on the incremental amount borrowed from $\$ 251$ $\$ 400$, and 10 percent on the incremental amount borrowed above $\$ 400$. The Lender and its main competitors charge those maximum allowed amounts on all loans. The annual percentage rate (APR) for a 14-day loan with 15 percent interest is 391 percent, meaning that borrowing $\$ 100$ over each of the approximately 26 two-week periods in a year would incur $\$ 391$ in interest. Regulations vary across states (NCSL 2019), although Indiana's price and loan size caps are close to the norm.

To take out a payday loan, borrowers must present identification, proof of income (e.g. a paycheck stub or direct deposit slip), and a post-dated check for the amount of the loan plus interest. Payday lenders do minimal underwriting, sometimes checking data from a subprime credit bureau. By law, payday lenders in Indiana must report all loans to a database managed by a company called Veritec. Lenders must check that database before disbursing loans to ensure that people do not borrow from more than two lenders at once. We ran our experiment in Indiana because we received regulatory approval to match consenting survey participants to their borrowing records from this database.

When the loan comes due, borrowers can repay (either in person or by allowing the lender to successfully cash the check) or default. Indiana law does not allow a loan to be "rolled over" into a new loan without first repaying, but borrowers can immediately get another loan after fully repaying the principal and interest owed on their previous loan. Per Indiana law, a borrower can get up to five consecutive loans from a given lender. After that, the borrower cannot take out a new loan from any lender for seven days. This rollover restriction has limited impact because it

\footnotetext{
${ }^{6}$ The strategy also builds on the key insights that motivate the parametric model in Acland and Levy (2012).
} 
lasts less than one pay cycle, so people can get another loan before they get close to running out of money as their next payday approaches.

In 2017, 80 percent of the Lender's loans nationwide were followed by another loan within the next eight weeks. In principle, people can borrow any continuous amount. In practice, most people make a binary decision to either reborrow the same amount or not get a new loan. Of all consecutive loans disbursed nationwide by the Lender in 2017, 68 percent of the subsequent loans were for the exact same amount as the previous loan, while 17 percent were for more and 15 percent were for less; see Appendix Figure A1. In the 32 percent of cases where the subsequent loan is for a different amount than the previous loan, the average difference between the loan amounts is only $\$ 1$. We will use this fact to simplify our model. ${ }^{7}$

If the borrower does not come to the store to repay the loan, the lender attempts to cash the post-dated check, and is allowed by state law to do so up to three times. For bounced checks, the borrower's bank will likely charge a fee of about $\$ 30$, and lenders in Indiana charge an additional $\$ 25$ bounced check fee. State law does not permit late fees. If the loan remains unpaid, the Lender's local staff try to work out a repayment plan with the borrower. If that fails, the Lender occasionally refers an account to a third-party collection agency. The Lender does not lend to people who have unpaid balances from past loan cycles.

Default is relatively rare on a per-loan basis: in 2017, only 3 percent of the Lender's loans ended in default. However, about 16 percent of sequences of consecutive loans ended in default in that year.

Payday lending has the hallmarks of a competitive market. Entry requires only modest physical capital, technology, and regulatory compliance relative to many other industries. There are about 300 payday lending stores in Indiana, of which the majority are owned by three national chains (Evans 2019). Despite high interest rates, risk-adjusted profits appear to be low: Ernst \& Young (2009) estimated pre-tax profit margins of less than 9 percent, with the majority of the costs due to defaulted loans (25 percent of costs) and operating costs (62 percent). Thus, market power is unlikely to be an economically meaningful distortion in this industry.

Substitutes for storefront payday loans include online loans, checking account overdrafts, auto title loans, pawn shops, loans from friends and family, and paying bills late. There is some disagreement across datasets about how much liquidity payday borrowers might have available on credit cards, which have much lower interest rates (Agarwal, Skiba, and Tobacman 2009; Bhutta, Skiba, and Tobacman 2015).

The Lender and its main competitors transparently disclose the interest and other fees, in both levels and APRs, both in stores and on their websites. Furthermore, the CFPB's 2017 regulation would limit the number of times that lenders can attempt to cash borrowers' checks, which generates the main fees that could be less salient to borrowers. For this reason, we do not study shrouded fees as a motivation for additional regulation.

\footnotetext{
${ }^{7}$ This is notable because depending on the distribution of income shocks, a standard model might predict that borrowers would gradually pay down the principal instead of repeatedly borrowing the same amount and then repaying in full.
} 


\section{EXPERIMENTAL DESIGN}

We designed the experiment to answer two key questions: whether people anticipate repeat borrowing, and whether people are willing to pay a premium for an incentive to avoid future borrowing.

The experiment ran at 41 of the Lender's stores in Indiana from January 7th through March 29th, 2019, for two weeks in each store. We piloted and refined the survey in fall 2018, including follow-up interviews with store staff and with people who had taken the survey to check their interpretation and understanding of the questions.

We contracted with EA Consultants, a financial health research company, to place a recruiter in each center on most days. The recruiter would approach customers either before or after they took out a loan and ask them to take a survey on an iPad. The iPad survey was self-contained, so the recruiters were only needed to recruit and answer questions if they arose. Perhaps as a result of the extensive piloting and refinement, the recruiters reported that they received essentially no questions about the survey.

Survey details. Appendix I presents the full survey instrument. To be eligible, a person must have taken out a payday loan from the Lender in Indiana in the past 30 days. After securing informed consent, the survey asked people's name and date of birth (to match to borrowing records) and email address (to send gift cards as payment for participation).

The first substantive question on the survey was to ask people to report the probability that they would take out another payday loan from any payday lender in the next 8 weeks. The possible answers were $0 \%, 10 \%, 20 \%, \ldots, 90 \%, 100 \%{ }^{8}$

The survey then introduced the first reward for completing the survey, "\$100 If You Are DebtFree." Participants were told that if they were selected for this reward, we would send them a Visa cash card 12 weeks from now if they did not take out another payday loan from any lender in the next eight weeks. The survey clarified that "All payday lenders are required to report loans to a database. We will use that database to check your borrowing from all payday lenders." We included a comprehension check question to make sure that participants understood the incentive. We then asked people to report the probability that they would take out another payday loan from any payday lender in the next eight weeks, if they were offered $\$ 100$ If You Are Debt Free; we call this $P$ in this section only.

Rewards and multiple price lists. After the belief elicitations were complete, the survey introduced the second possible reward: a certain payment that we called "Money for Sure." Just as with the $\$ 100$ If You Are Debt Free reward, Money for Sure would be paid within 12 weeks on a Visa cash card. The survey then walked participants through an adaptive series of questions to determine their valuations of the no-borrowing incentive. The first question asked whether the

\footnotetext{
${ }^{8}$ In a pilot, we found that participants were more likely to answer $0 \%, 50 \%$, and $100 \%$ when they could report any number from 0-100 in an open-answer box. Because this kind of rounding generates measurement error (see Appendix B.1), we decided that the equally neutral approach of simply giving people 11 options would elicit beliefs with greater precision.
} 
person would prefer to receive the no-borrowing incentive or an amount of Money for Sure equal to the incentive's expected value. We helped people to calculate that expected value and highlighted the non-financial reasons why they might prefer a certain payment versus a no-borrowing incentive. The survey read,

Earlier, you told us that you have a $[P] \%$ chance of getting another payday loan before [8 weeks from now] if you are selected for $\$ 100$ If You Are Debt-Free. In other words, you would have a $[100-P] \%$ chance of being debt-free. So on average, $\$ 100$ If You Are Debt-Free would earn you $\$[100-P]$.

Given that, which reward would you prefer?

- $\$ 100$ If You Are Debt-Free. This gives you extra motivation to stay debt-free.

- $\$[100-P]$ For Sure. This gives you certainty and avoids pressure to stay debt-free.

One possible concern with this language is that by clarifying the reasons why they might prefer the incentive ("extra motivation") or the Money for Sure ("gives you certainty and avoids pressure"), we might generate an experimenter demand effect toward one option or the other. Our judgment was that this concern was outweighed by the experimental value of orienting people to the relevant considerations, and we intentionally wrote this language in a balanced way that does not favor either of the two options. ${ }^{9}$

The survey then sequentially offered choices with different amounts of Money For Sure in order to bound the amount at which the borrower was indifferent between the certain payment and $\$ 100$ If You Are Debt-Free. ${ }^{10}$

The third possible reward for completing the survey was called Flip a Coin for $\$ 100$. Participants who were selected for this reward would have a 50 percent chance of winning $\$ 100$ and a 50 percent chance of winning nothing. This would also be paid within 12 weeks on a Visa cash card. The survey led participants through an analogous adaptive question procedure, beginning with a tradeoff between Flip a Coin for $\$ 100$ and $\$ 50$ For Sure. People's valuations of Flip a Coin for $\$ 100$ from this procedure provide a measure of risk aversion.

\footnotetext{
${ }^{9}$ One more subtle potential concern is that the experiment makes commitment opportunities salient to borrowers who would otherwise be inattentive to their present focus. However, this is desirable for inferring the structural parameters of a present focus model, as our measurement of the degree of present focus is most accurate when borrowers are actually aware of it. Note that borrowers' forecasts of their behavior are elicited before they encounter this frame, and it is their forecasts that identify the degree of sophistication or naivete.

${ }^{10}$ Because the survey allowed probabilities $P$ to take values $0 \%, 10 \%, \ldots, 90 \%, 100 \%$, the initial offer of Money For Sure could take values from $\$ 0, \$ 10, \ldots, \$ 90, \$ 100$. If the borrower preferred the no-borrowing incentive over $100-P$ For Sure, the survey would offer another choice with $100-P+20$. If the borrower preferred $100-P+20$, the survey would offer $100-P+40$. If the borrower preferred $100-P+40$, the survey would backtrack to $100-P+10$ to avoid giving the mistaken impression that this was a bargaining game. Once the borrower preferred $x$ For Sure over the no-borrowing incentive, the survey would offer $x-10$ for Sure. After that question, the borrower's valuation of incentive would be bounded within a $\$ 10$ range. The algorithm worked analogously if the borrower initially preferred $100-P$ For Sure over the no-borrowing incentive.
} 
Attention check and qualitative questions. Immediately after this second MPL, there was an attention check question in which the text asked people to click the "next" button instead of answering. The survey ended with three qualitative questions designed to elicit intuitive measures of desired motivation to avoid future borrowing and of past misprediction of payday borrowing.

Randomization and incentive compatibility. The computer used people's responses on the two adaptive procedures to fill out two multiple price lists (MPLs) with amounts of Money for Sure ranging from $\$ 0$ to $\$ 160$ in increments of $\$ 10$. Although all participants completed the MPLs, only two percent of survey respondents (the "MPL group") were ex-post randomly assigned to receive the choice they made (or would have made) on a randomly selected row from one of the two MPLs. Because all participants had a chance of having their MPL decisions determine their outcomes, it was incentive compatible for participants to answer all questions truthfully. We informed people of this before beginning the questions, saying "Think carefully, because the computer may randomly select one of the following questions and give you what you chose in that question." People could click to a separate page for full implementation details.

We did not incentivize belief elicitations because truthful reporting is not incentive compatible for individuals who perceive themselves to be time inconsistent. A person who thinks that she borrows too much should report a borrowing probability that is lower than her actual belief, to incentivize her future self to borrow less. ${ }^{11}$

The randomization assigned participants to $\$ 100$ If You Are Debt-Free (the "Incentive group"), no reward (the "Control group"), or the MPL group with 44, 54, and 2 percent probability, respectively. Participants were randomized if they had "valid" survey data under four pre-registered criteria: (i) if they passed both the no-borrowing incentive comprehension check and the attention check, (ii) did not make inconsistent choices on either of the two MPLs, and (iii, iv) had certainty equivalents of less than $\$ 160$ on each of the two MPLs.

Post-survey. After the survey was complete, the iPad informed participants of whether they had been selected for a reward. Each day, we matched surveys to the Lender's records. Participants whose name and birth date could be matched to a payday loan disbursed by the Lender in the past 30 days were sent an email thanking them for participating and a reminder of any reward that they had received. They also received a separate email from our gift card vendor explaining how to claim their $\$ 10$ gift card. People who began the survey but failed to complete it received an email encouraging them to complete their survey from where they had left off. People who took out payday loans from a store on a day when the survey was available in that store were emailed a link to take the survey online.

After four weeks, all participants received a second email, including a reminder of any reward that they had received. After eight weeks, we received borrowing records from the Veritec statewide database. By no more than 12 weeks after the survey (in practice, typically at 10 weeks), people

\footnotetext{
${ }^{11}$ Although Augenblick and Rabin (2019) show that this distortion is bounded in deterministic, continuous-effort settings, this does not generalize to our stochastic discrete choice setting.
} 
who had received Money For Sure or had been offered $\$ 100$ If You Are Debt-Free and had not borrowed were sent an email from our gift card vendor explaining how to claim their cash cards.

\section{DATA}

\subsection{Survey and borrowing data}

13,191 people took out payday loans from one of the Lender's stores on a day when the survey was available in that store. We have the Lender's records for those 13,191 loans, plus all loans from 2012 through February 2018 for a random sample of the Lender's customers nationwide who took out payday loans either online or in storefronts. The Lender's data include income, an internal credit score on a scale from 0-1000, pay cycle length, loan length, and loan amount. For our analyses using the Lender's nationwide data, we use all loans disbursed in 2017, the most recent complete year. From the statewide payday lending database managed by Veritec, we also observe whether each survey participant got another loan from any lender over the next eight weeks after they took the survey. Payday borrowers typically borrow from only one lender, and reborrowing rates are almost exactly the same whether calculated with the Lender's data or with the Veritec data. Appendix Table A1 presents more information on our key variables and their sources. Appendix Table A2 documents that the Incentive and Control groups are balanced on observables.

Of the 13,191 people who took out loans on survey days in survey stores, 2,236 consented and 2,122 completed the survey, of whom 1,205 had valid survey data under the four pre-registered criteria introduced in Section 4. See Appendix Table A3 for details. Unless otherwise noted, figures and tables in the paper are limited to the 1,205 borrowers with valid data, following our pre-registered sample inclusion criteria. ${ }^{12}$ Three percent of surveys were completed by borrowers who had not responded in the store and were invited by email. Although our valid sample comprises only a small share of customers who could have taken the survey, Table 1 shows that they are comparable on our observable characteristics to the 13,191 borrowers on survey days and to the Lender's borrowers nationwide in 2017. The average loan length in our survey sample is 16 days, the average loan amount is $\$ 373$, and borrowers' average annual income is about $\$ 34,000$.

To cleanly compare predicted and actual borrowing, our survey participants' borrowing after the survey must not be affected by unexpected common shocks. For example, if unemployment suddenly rose in the two months after the survey, this could cause an unpredicted borrowing increase that our framework would attribute to naivete. Appendix Figure A4 shows that in Indiana over the study period, per-capita income growth was steady and unemployment varied by only 0.1 percentage points.

We say that borrowers reborrowed if they were issued another loan from any payday lender at any point between the day they took the survey and eight weeks after the survey. We say that borrowers defaulted on a loan if they did not pay off all principal and fees owed. We say that borrowers repaid if they did not reborrow or default - that is, if they did not owe debt to a payday

\footnotetext{
${ }^{12}$ The pre-registration is available at www.socialscienceregistry.org/docs/analysisplan/2037.
} 
lender at any point between the day their current loan (at the time of the survey) came due and eight weeks after the survey. We define a loan sequence (or borrowing spell) as a series of loans with no more than eight weeks between any two loan disbursals.

\subsection{Expert survey}

Before releasing our paper, we elicited predictions of our results and opinions about payday lending regulation from a sample of domain experts, following recent work by DellaVigna and Pope (2018) and others. We surveyed both academic and non-academic experts. For academics, our sample frame was behavioral and household finance economists we cited in our April 2019 draft, plus participants before two seminar presentations in April 2019. For non-academic experts, the sample frame was (i) the chief consumer finance regulator in each of the 50 states plus DC, (ii) the lead staff person for each Congressperson and Senator on the federal House and Senate financial services committees, (iii) researchers and regulators working on consumer lending and credit from the CFPB and the Department of Defense, and (iv) leadership and head payday lending experts at five major think tanks (the Pew Center, the Center for Financial Services Innovation, the Consumer Federation of America, the National Consumer Law Foundation, and the Center for Responsible Lending).

The survey began with a detailed description of our study's context and sample, followed by two sets of questions. First, we elicited opinions about whether three common types of payday lending regulation were good or bad for consumers, and the certainty that the expert had in her answer. Second, we elicited predictions of our empirical results. To elicit expert beliefs about borrowers' misprediction, we asked if the experts thought that the average payday loan borrower underestimates, overestimates, or correctly foresees the chance that she will reborrow in the future. We then told experts that borrowers in our data had about a 70 percent chance of reborrowing over the next eight weeks, and asked for their estimate of borrowers' average predicted reborrowing probability. ${ }^{13}$ To elicit expert beliefs about borrowers' demand for behavior change, we asked if the experts thought that "the average payday loan borrower would want to give herself extra motivation to avoid reborrowing." For experts who reported that they had a $\mathrm{PhD}$ in economics, we also elicited their estimate of borrowers' average $\tilde{\beta}$ parameter.

We had 103 respondents, of whom 68 percent work at a university and have a $\mathrm{PhD}$ in economics. See Appendix Table A4 for descriptive statistics. Appendix J presents the full expert survey instrument.

\section{REDUCED-FORM EMPIRICAL RESULTS}

This section presents answers to our two key empirical research questions using only minimal modeling assumptions.

\footnotetext{
${ }^{13}$ We said 70 percent because we did not yet know the sample average reborrowing probability when we fielded the expert survey.
} 
Figure 1 illustrates the framework guiding our analysis. The x-axis is the probability of borrowing in the next eight weeks, and the y-axis is the cost of borrowing. There are three demand curves: actual, predicted, and desired. In a standard model of time-consistent consumers with rational expectations, these three curves coincide. Actual and predicted demand differ if people mispredict future borrowing due to naivete about self-control problems, overoptimism about or inattention to future income or expenditure needs, or any other reason. Predicted and desired demand differ if people perceive themselves to be time inconsistent.

The scalars $b$ and $w$, respectively, denote possible amounts of the no-borrowing incentive and Money for Sure. We define $\mu(b)$ and $\tilde{\mu}(b)$ as the actual and predicted probabilities of reborrowing over the next eight weeks. We define the function $w(b)$ as the valuation of a no-borrowing incentive of amount $b$, i.e. the $w(b)$ such that the borrower would be indifferent between a $b$ dollar noborrowing incentive and $w(b)$ dollars of Money for Sure.

\subsection{Do borrowers anticipate repeat borrowing?}

We begin by comparing predicted and actual borrowing for the Control group, i.e. the borrowers in the standard environment without the experimental no-borrowing incentive. Figure 2 shows that the average borrower predicts she has a $\tilde{\mu}(0) \approx 70$ percent chance of borrowing without the incentive, while in reality, $\mu(0) \approx 74$ percent of borrowers in the Control group did borrow. ${ }^{14}$ This implies that the average borrower almost fully anticipates repeat borrowing. ${ }^{15}$

This slightly underestimated borrowing probability is consistent with responses to an additional qualitative survey question. When asked how their past expectations of payday loan usage had lined up with reality, 36, 25, and 39 percent of borrowers reported getting payday loans "more often than I expected," "less often than I expected," and "about as often as I expected," respectively. With rational expectations, one would expect equal shares of "more often" and "less often."

Figure 3 presents misprediction as a function of recent borrowing experience. The four experience groups are approximately quartiles of the experience distribution in our sample. Borrowers who had gotten three or fewer loans in the previous six months underestimate future borrowing by 20 percentage points, whereas borrowers with four or more recent loans predict close to correctly on average. ${ }^{16}$ This is consistent with borrowers learning from experience. ${ }^{17}$

\footnotetext{
${ }^{14}$ The samples in the left and right spikes of Figure 2 are different in that the left spike includes the full sample while the right spike includes the (randomly assigned) Control group only. This makes little difference because there is only minimal sampling error: the Control group's predicted borrowing probability without the no-borrowing incentive is 69 percent.

${ }^{15}$ Although our pre-registered exclusion restrictions could in principle be correlated with misprediction, we find that is not the case: Appendix Figure A10 shows that the results are similar when we do not apply the restrictions.

${ }^{16}$ Over-optimistic beliefs are sometimes attributed to aspirational reporting, where time-inconsistent people misreport beliefs in order to encourage future behavior change (Augenblick and Rabin, 2019). The fact that experienced borrowers are statistically unbiased on average suggests that this and related reporting biases did not affect their reports, although such factors could in principle affect less experienced borrowers.

${ }^{17}$ Appendix Figure A11 shows qualitatively similar results after defining experience to be the number of previous loans in the current borrowing spell. Appendix Figure A12 shows that the decrease in misprediction with experience is driven mostly by higher predicted borrowing probability, not lower actual borrowing probability. Appendix Figure A13 shows that misprediction does not differ statistically by internal credit score or income.
} 
Table 2 presents regressions that quantify and extend this result. The dependent variable in the first four columns is misprediction, $R_{i}-\tilde{\mu}_{i}(0)$, where $R_{i}$ is an indicator for whether person $i$ got another payday loan in the next eight weeks, and the sample includes only the Control group. Column 1 estimates a linear version of Figure 3. One additional loan in the past six months is associated with 2.74 percentage points less underestimation of future borrowing probability.

Because experience is not randomly assigned, we do not know if these results reflect learning from experience or unobserved factors that are correlated with both past borrowing and misprediction. Column 2 of Table 2 shows that the misprediction-experience relationship is robust to controlling for all observables in the Lender's data - annual income, internal credit score, pay cycle length, loan length, and loan amount - as well as whether the participant took the survey in the store and the valuation of the $\$ 100$ coin flip. This is consistent with the relationship being driven by learning instead of other factors, although there of course may be additional unobservables. Our present focus model in Sections 7 and 8 predicts that in the absence of learning, sophisticated types reborrow less, which would imply that the effect of experience on misprediction is even larger than the correlation between the two variables.

To what extent is the misprediction-experience relationship driven by recent experience in the current borrowing spell versus prior experience? Columns 3 and 4 separate the loans in past six months into loans in current borrowing spell versus loans before the current borrowing spell. Both types of experience are statistically associated with less misprediction, and the magnitudes are statistically indistinguishable. Column 4 shows that both associations are robust to the inclusion of controls.

Our evidence differs from evidence of substantial and more persistent naivete in other settings. ${ }^{18}$ One potential explanation is that learning is context-specific, and payday borrowing is a high-stakes domain with clear feedback and repeated learning opportunities. ${ }^{19}$

Appendix B further explores borrowers' beliefs, showing that predicted and actual borrowing are positively correlated. This relationship is attenuated relative to a 45-degree line because of survey response noise due to rounding and other cognitive difficulties in articulating probabilities. However, we show in the appendix that this does not bias our estimate of individuals' average forecast, because rounding leads to approximately mean-zero measurement error in people's true subjective beliefs.

Our expert survey respondents believed that borrowers would be much more naive than they

\footnotetext{
${ }^{18} \mathrm{~A}$ key caveat is that we cannot rule out the possibility that borrowers underestimate the size of their loan conditional on reborrowing. However, we think it is unlikely that borrowers learn their likelihood of reborrowing but stay significantly miscalibrated about how much they reborrow, especially because borrowers reborrow exactly the same amount 68 percent of the time.

${ }^{19}$ Settings where significant naivete has been documented include real-effort laboratory experiments (Augenblick and Rabin 2019), which are low-stakes one-shot settings, and gym attendance (DellaVigna and Malmendier 2004; Acland and Levy 2015; Carrera et al. 2021), which has repeated learning opportunities but relatively low stakes. Kaur, Kremer, and Mullainathan (2015) and Yaouanq and Schwardmann (2019) find that people become more sophisticated over time in experiments with clear and salient feedback. Theoretical models show that learning is enhanced by stakes in the presence of partial commitment devices (Ali 2011), or by the possibility of many future contracting opportunities (Gagnon-Bartsch, Rabin, and Schwartzstein 2019).
} 
actually are. 78 percent of our respondents thought that the average borrower underestimates reborrowing. Figure 4 presents the distribution of respondents' beliefs about borrowers' average predicted reborrowing probability. The average respondent thought that the average borrower would predict only a 40 percent chance (standard error $\approx 2.1$ percent) of reborrowing over the next eight weeks, a 30 percentage point misprediction relative to the 70 percent reborrowing probability we told the experts. This contrasts sharply with the limited misprediction documented in Figure 2 .

\subsubsection{Misprediction in Incentive condition}

A related but different question is whether people correctly predict their borrowing in the Incentive condition. The average borrower predicts that she has only a $\tilde{\mu}(100) \approx 50$ percent chance of borrowing if offered the no-borrowing incentive, while in reality, $\mu(100) \approx 70$ percent of borrowers in the Incentive group did borrow. Putting this together with the averages in Figure 2, this implies that the average borrower predicts that the no-borrowing incentive would reduce borrowing by $\tilde{\mu}(0)-\tilde{\mu}(100) \approx 20$ percentage points, whereas in reality, the incentive reduced borrowing by only $\mu(0)-\mu(100) \approx 3.8$ percentage points.

There are several potential explanations. First, even if borrowers correctly predict their status quo borrowing probability, they might overestimate their demand response if liquidity shocks have higher variance than they realize. Indeed, because of the lack of price variation in the payday loan market, borrowers have little opportunity to learn their price elasticity and little incentive to attend to information that would help them identify this elasticity. Second, because the experimental incentive is new and unfamiliar, borrowers may have forgotten about it and failed to predict that they would forget. ${ }^{20}$ Indeed, although our participants are liquidity constrained and we sent two reminder emails, our gift card vendor reports that only 44 percent of the $\$ 100$ gift cards were claimed, compared with 76 percent of the $\$ 10$ gift cards given as participation payments the day after the survey. Third, experimenter demand effects could have caused people to overstate their beliefs about the effect of the incentive, although this seems least likely.

Appendix Figure A14 shows that there is no relationship between experience and misprediction in the Incentive condition, and even experienced borrowers underestimate borrowing in that condition. This suggests that learning is context-specific. Experience under normal conditions may help borrowers to predict their behavior in normal conditions, but it does not help them predict their behavior in unfamiliar conditions.

Although people substantially overestimate the incentive's effect, they do have some information about how it would affect them. Figure 5 presents estimates of the average predicted and actual effects of the incentive separately for people who reported that the incentive would reduce their borrowing and people who reported that it would not. The low predicted response group correctly

\footnotetext{
${ }^{20}$ Our finding is reminiscent of Ericson (2011) in which a large sample of students faces a similarly unfamiliar choice. In that paper, participants' choices imply that on average they forecasted a 76 percent claim rate of a monetary reward after a six-month delay, although only 53 percent claimed it in reality.
} 
predicts that the incentive will not affect their borrowing, and the high predicted response group correctly predicts that the incentive will reduce their borrowing, but the latter group substantially overestimates the actual effect.

The bulk of the evidence suggests that misprediction in the Incentive condition is not informative about misprediction under standard conditions outside the experiment: it appears to be driven by the unusual nature of the experimental incentive. Thus, we use only the misprediction in the status quo Control condition to identify naivete. Our estimates in Sections 6.2 and 7 rely only on the assumption that on average (up to mean-zero noise), people accurately reported their subjective beliefs about the effect of the incentive on borrowing; the fact that these subjective beliefs turn out to be mistaken does not bias our estimates. ${ }^{21}$

\subsection{Do borrowers perceive themselves to be time consistent?}

\subsubsection{Graphical intuition}

To identify perceived time inconsistency, we extend Carrera et al. (2021) to our dynamic setting with income effects. Using people's predictions of their future behavior, we can calculate what their valuation of the no-borrowing incentive would be if they were time consistent. People who believe that they are time inconsistent and that their future selves will borrow more than they presently prefer will place an additional premium on the incentive, because they value the fact that the incentive will induce their future selves to borrow less.

More precisely, our strategy exploits the fundamental link between time consistency and the Envelope Theorem for dynamic optimization. A time-consistent person's expected utility is unaffected by marginal changes in her future behavior, since her future behavior maximizes her current utility function (by definition). Thus, a time-consistent borrower's valuation of a marginal no-borrowing incentive equals the mechanical effect of the incentive on cash-on-hand; the induced marginal behavior change has no effect. By contrast, future behavior changes do have first-order effects on the expected utility of time-inconsistent people because they do not share the preferences of their future selves. Thus, a time-inconsistent borrower's valuation of the no-borrowing incentive will include the additional behavior change effect.

For intuition, examine Figure 1 and temporarily assume that borrowers are risk neutral. A no-borrowing incentive of size $b$ is equivalent to giving people $b$ while also increasing the price of borrowing by $b$. Thus, a time-consistent borrower values the incentive at $b$ minus the consumer surplus loss from increasing the price of borrowing by $b$. On the figure, this consumer surplus loss is area $\mathrm{ABCD}$. Thus, borrowers who perceive themselves to be time consistent will value the incentive at $b-A B C D$ dollars.

We let $w^{*}(b):=b-A B C D$ denote the valuation that borrowers would have if they were riskneutral and perceived themselves to be time consistent. We can write this as

\footnotetext{
${ }^{21}$ We explore sensitivity to this assumption in Appendix E.6.
} 


$$
w^{*}(b):=b-b \frac{\tilde{\mu}(0)+\tilde{\mu}(b)}{2},
$$

where $\tilde{\mu}(0)$ and $\tilde{\mu}(b)$ are the perceived borrowing probabilities without and with the incentive.

Borrowers who perceive themselves to be time-inconsistent predict that they will have different preferences in the future than they do when they take the survey. The figure captures this by distinguishing between predicted and desired demand. As drawn, desired demand is shifted inward, meaning that borrowers want their future selves to borrow less. The perceived utility gain from a marginal behavior change is the vertical distance between predicted and desired demand, which integrates to the trapezoid ABEF over the behavior change induced by the the no-borrowing incentive. Thus, borrowers who perceive themselves to be time inconsistent will value the incentive at $b-A B C D+A B E F>w^{*}(b)$. In theory, borrowers could perceive that their future selves will borrow too little, giving valuations less than $w^{*}(b)$.

So far, this assumes that borrowers are risk-neutral. Since the no-borrowing incentive is risky, risk aversion would lower valuations of the incentive. Thus, we have a one-sided test of time inconsistency: valuations above $w^{*}(b)$ are consistent with perceived overborrowing, while valuations below that bound could be consistent with perceived underborrowing and/or risk aversion. In Section 7, we impose additional structure to tighten the bound and allow two-sided tests.

In Appendix D, we formalize this graphical intuition and the implications of risk aversion using the general Envelope Theorem results developed by Milgrom and Segal (2002) for arbitrary choice sets. As we show in that appendix, $w^{*}(b)$ constitutes an upper bound on a risk-averse person's valuation of the incentive under relatively weak assumptions and across a broad class of dynamic stochastic models of individual behavior.

This approach is related to but different from the approach of testing for time-inconsistency by eliciting demand for "dominated" commitment contracts that time-consistent people should not want, such as a commitment to pay $\$ 100$ if one fails to quit smoking or go to the gym. ${ }^{22}$ Such tests can deliver false negatives because uncertainty and demand for flexibility reduce demand for such contracts (Heidhues and Köszegi 2009; Laibson 2015; Carrera et al. 2021), and they can deliver false positives because of noise in takeup decisions (Carrera et al. 2021). Building on Carrera et al. (2021), our approach avoids these drawbacks by analyzing the average valuation of a commitment device instead of the share of consumers who choose it at a given price and accounting for uncertainty by eliciting and modeling predicted behavior $\tilde{\mu}$.

\subsubsection{Empirical results}

Figure 6 presents the key moments that identify time inconsistency. The first spike shows that the average borrower in our sample values the $\$ 100$ no-borrowing incentive at $\$ 52$. The second spike is the valuation for risk-neutral and time-consistent borrowers from Equation (13): $w^{*}(100)=$

\footnotetext{
${ }^{22}$ This literature includes Ashraf, Karlan, and Yin (2006), Beshears et al. (2015), Duflo, Kremer, and Robinson (2011), Gine, Karlan, and Zinman (2010), John (forthcoming), Kaur, Kremer, and Mullainathan (2015), Royer, Stehr, and Sydnor (2015), and Schilbach (2019).
} 
$\left(1-70 \%+\frac{70 \%-50 \%}{2}\right) \times \$ 100 \approx \$ 40$ on average. In other words, if borrowers were risk-neutral and believed that they were time consistent, their average valuation of the no-borrowing incentive would be $\$ 40$. If borrowers are risk-averse, their average valuation of the incentive would be less than $\$ 40$. Since the $\$ 52$ average valuation exceeds $\$ 40$, we infer that the average borrower is either risk seeking or perceives herself to be time inconsistent. We refer to the difference between these first two spikes, i.e. $w(100)-w^{*}(100)$, as the "behavior change premium." This is $\$ 12$ on average, or 30 percent more than $w^{*}(100)$.

The third spike on Figure 6 shows that the average borrower is willing to pay $\$ 42$ for the $\$ 100$ coin flip. This implies material risk aversion. Thus, the $\$ 12$ behavior change premium could be a loose lower bound on borrowers' actual valuation of the behavior change induced by the incentive. ${ }^{23}$

This perceived time inconsistency is consistent with qualitative survey responses. Panel (a) of Figure 7 shows that 54 percent of people report that they would "very much" like to give themselves extra motivation to avoid future payday loan debt, 36 percent report "somewhat," and only 10 percent "not at all." Panel (b) shows that although most people want motivation to avoid payday loan debt, people are more likely to think that restrictions on repeat borrowing would be bad for them. This is consistent with uncertainty about liquidity shocks creating a need for flexibility. Responses to these two questions are correlated: people who want more motivation are more likely to think that borrowing restrictions would be good for them.

Figure 8 shows that the behavior change premium is correlated with other survey responses in expected ways. $^{24}$ People who report that they want more motivation to avoid payday loan debt, that a rollover restriction would be good for them, or that the incentive will reduce their probability of borrowing have higher behavior change premia. ${ }^{25}$ These results build confidence in the conclusion that borrowers perceive themselves to be time inconsistent.

In Section 6.1, we saw that misprediction decreases with experience. If this reflects borrowers learning that they are time inconsistent, one might expect that the behavior change premium would be higher for experienced consumers. Columns 5 and 6 of Table 2 show that this is indeed the case: one additional loan of experience in the past six months is associated with a $\$ 1.09$ higher behavior change premium, and adding controls has little effect on this relationship. In all regressions with the behavior change premium, we also control for predicted demand response. Consistent with Figure 8 , borrowers who predict that the no-borrowing incentive will reduce their chance of borrowing have $\$ 12-\$ 13$ higher behavior change premia.

Interestingly, columns 7 and 8 show that the number of loans before the current spell is more strongly associated with the behavior change premium than loans in the current spell. This con-

\footnotetext{
${ }^{23}$ Appendix Figures A2 and A3 present the distributions of valuations of the no-borrowing incentive and coin flip.

${ }^{24}$ The behavior change premium does not differ statistically by internal credit score or income; see Appendix Figure A15.

${ }^{25}$ When eliciting valuations of the no-borrowing incentive, we explained that it "gives you extra motivation to stay debt-free," which is similar to the language in the qualitative question about "giving yourself extra motivation to avoid payday loan debt." However, it is unlikely that the correlation in responses to these two questions is just a mechanical result of framing, because the behavior change premium is also correlated with borrowers thinking that the rollover restriction would be good for them, and with borrowers predicting a larger reduction in borrowing probability.
} 
trasts with their statistically equal relationship with misprediction in columns 3 and 4 . Through the lens of the present focus model, a literal interpretation of these results is that time inconsistency, but not misprediction, has a larger effect on starting borrowing spells than on extending them.

\section{STRUCTURAL ESTIMATES OF PRESENT FOCUS AND NAIVETE}

\subsection{Setup}

The previous section showed that misperceived borrowing and perceived time inconsistency can be identified in our data with minimal assumptions. In this section, we use similar identification approaches and additional assumptions to estimate a structural model of borrowers' time preferences and beliefs.

We assume that borrowers have quasi-hyperbolic preferences given by $U_{t}=u_{t}+\beta \sum_{\tau=t+1}^{T} \delta^{\tau-t} u_{\tau}$, where $u_{t}$ is the period $t$ utility flow. Following O'Donoghue and Rabin (2001), we allow people to mispredict their preferences: in all periods $t<\tau$, they predict that their period $\tau$ self will have short-run discount factor $\tilde{\beta}$. We discuss other misprediction models in Appendix E.5.

Our model builds on Heidhues and Koszegi (2010). Figure 9 illustrates. We focus on three periods of a potentially longer or infinite-horizon model. In period 0 , the borrower gets a loan of amount $l$ and then takes our survey. The next eight weeks after the survey are period 1 . At the beginning of period 1 , the borrower receives a smoothly distributed transitory repayment cost shock $\theta$. This shock captures expenses (such as car repairs) and income shocks (such as being scheduled for fewer hours at work) that are unpredictable as of period 0 . In period 1 , the borrower chooses to either repay or reborrow. If she repays, she pays the principal and fee $l+p(l)$ in period 1 and receives no-borrowing incentive $b$ in period 2 . If she reborrows, she pays only the fee $p(l)$ in period 1 , owes $l+p(l)$ in period 2 , and does not receive the no-borrowing incentive.

The cost of repaying amount $x$ in period 1 is a smooth function $k(x, \theta)$ that is convex in $x$ and strictly increasing in $\theta$. The $x$ in $k(x, \theta)$ equals $p(l)$ if the borrower reborrows in period 1 and equals $l+p(l)$ if the borrower repays.

The cost of starting period 2 with debt $x$ is denoted $\tilde{C}(x)$; specifically, this is the reduction in period 2 continuation value (as perceived before period 2) from starting period 2 with debt $x$ instead of being debt-free. ${ }^{26}$ The $x$ in $\tilde{C}(x)$ equals $l+p(l)$ if the borrower reborrows in period 1 and equals $-b$ if the borrower repays and is owed an incentive payment. The assumption of a well-behaved function $\tilde{C}$ is far from innocuous when $\tilde{\beta}<1$, because $\tilde{C}$ is the solution to a non-cooperative game played between the different selves after period 2 (Harris and Laibson 2001; Laibson et al. 2015). In Appendix F.1, we show existence, uniqueness, and smoothness of $\tilde{C}$ in the fully dynamic model presented in Section 8.

\footnotetext{
${ }^{26}$ Formally, if $\tilde{V}_{2}(x)$ is the perceived period 2 continuation value function as a function of period $t \operatorname{debt} x, \tilde{C}(x)=$ $\tilde{V}_{2}(0)-\tilde{V}_{2}(x)$. We say "perceived" continuation value function because people mispredict their behavior (and thus their utility) if $\tilde{\beta} \neq \beta$. For simplicity, the exposition in this section assumes that the borrower has the same expectation of $\tilde{C}$ in both periods 0 and 1 . However, the proofs of this section's results in Appendix E allow for certain types of correlated shocks that reveal additional information about $\tilde{C}$ in period 1 .
} 
These three periods could correspond to any three periods in an infinite-horizon model, such as the one we present in Section 8. We do not need to observe or explicitly model decisions in period 2 or later, as the period 2 continuation value is captured in $\tilde{C}$.

Three assumptions of this framework should be made explicit. First, people cannot get a loan of any amount other than $l$ in period 1. This is realistic because as discussed in Section 3, most people either repay or reborrow the same amount as their previous loan. ${ }^{27}$ Second, borrowers cannot default in period 1. This is a reasonable approximation because the probability of default on any one loan is only 3 percent. The microfounded model in Appendix F.1 allows people to default in period 2 or later, so the possibility of default can influence period $2 \operatorname{debt} \operatorname{cost} \tilde{C}$. Third, borrowers have only one borrowing decision in period 1 , even though that period is eight weeks long.

\subsection{Graphical illustration with risk neutrality}

In this sub-section, we return to Figure 1 to illustrate the identification. For this graphical illustration only, we assume that borrowers are risk-neutral, or more precisely that period 2 debt cost $\tilde{C}$ is linear. We can now discuss the three demand functions on the figure in the context of the model. The period 1 self determines actual demand; that self discounts period 2 debt cost $\tilde{C}$ by $\beta \delta$ relative to period 1 utility. The period 0 self predicts that the period 1 self will instead discount $\tilde{C}$ by $\tilde{\beta} \delta$, so the ratio of predicted to actual marginal utility (i.e. the ratio of the heights of predicted vs. actual demand curves) is $\beta / \tilde{\beta}$. The period 0 self would prefer that the period 1 self $\operatorname{discount} \tilde{C}$ by only $\delta$ instead of the predicted $\tilde{\beta} \delta$ relative to period 1 utility, so the ratio of desired to predicted marginal utility is $\tilde{\beta}$.

\subsubsection{Identifying sophistication versus naivete}

In Section 6.1, we compared predicted and actual demand to identify misprediction in probability units. We now identify the relationship between $\beta$ and $\tilde{\beta}$ by transforming misprediction into marginal utility units using the perceived demand slope.

Define $b^{\dagger}$ such that $\tilde{\mu}\left(b^{\dagger}\right)=\mu(0)$. In words, $b^{\dagger}$ is the no-borrowing incentive at which predicted demand with the incentive would equal actual demand without the incentive. Define $\tilde{\Delta}(b):=$ $\tilde{\mu}(0)-\tilde{\mu}(b)$ as the predicted effect of the incentive on borrowing. Under a linear approximation, the perceived demand slope is $\frac{-\tilde{\Delta}}{b}$, the definition of $b^{\dagger}$ can be written as $\tilde{\mu}(0)+b^{\dagger} \frac{-\tilde{\Delta}}{b}=\mu(0)$, and thus

$$
b^{\dagger}=\frac{b}{-\tilde{\Delta}}(\mu(0)-\tilde{\mu}(0)) .
$$

\footnotetext{
${ }^{27}$ In a more general model where borrowers could choose some other loan amount $l^{\prime}$, the average differences between actual, predicted, and desired demand depend (to a first-order approximation) on the average of $l^{\prime}+p$. In the Lender's data, conditional on reborrowing a different amount, the average amount reborrowed is only $\$ 1$ different than the average previous loan amount. Thus, it is a close approximation to assume that when people re-borrow, they always reborrow exactly $l+p$.
} 
This shows how $b^{\dagger}$ transforms misprediction $\mu(0)-\tilde{\mu}(0)$ into dollar units using the perceived demand slope $\frac{b}{-\tilde{\Delta}}$.

In Figure $1, b^{\dagger}$ is the vertical distance between points $\mathrm{H}$ and $\mathrm{G}$, the predicted and actual demand curves at probability $\mu(0) . b^{\dagger}>0$ implies that people overestimate future borrowing, while $b^{\dagger}<0$ implies that people underestimate borrowing. From Section 6.1 , we know that $b^{\dagger}<0$ on average in the data.

We can also write $b^{\dagger}$ as a function of $\beta$ and $\tilde{\beta}$. For $b^{\dagger}$ to equate actual demand at zero incentive with predicted demand at incentive $b^{\dagger}$, it must equate the actual reborrowing cost from the perspective of the period 1 self with the period 0 self's prediction of that reborrowing cost with incentive $b^{\dagger}$ :

$$
\underbrace{\beta[\tilde{C}(l+p)-\tilde{C}(0)]}_{\text {period } 1 \text { self's reborrowing cost }}=\underbrace{\tilde{\beta}\left[\tilde{C}(l+p)-\tilde{C}\left(-b^{\dagger}\right)\right]}_{\text {predicted reborrowing cost with incentive } b^{\dagger}}
$$

Re-arranging and exploiting linearity in $\tilde{C}(x)$ gives an intuitive formula for sophistication - the ratio of actual to perceived present focus:

$$
\frac{\beta}{\tilde{\beta}}=\frac{l+p+b^{\dagger}}{l+p} .
$$

Both the left-hand side and right-hand side of this equation are the ratio of the height of $H$ to the height of $\mathrm{G}$ in Figure 1, i.e. the ratio of predicted to actual marginal utility at probability $\mu(0)$. If people correctly predict borrowing on average, $b^{\dagger}=0$ and $\beta / \tilde{\beta}=1$. We infer lower $\beta / \tilde{\beta}$ (more naivete) when $b^{\dagger}$ is more negative (people more heavily underestimate future borrowing).

\subsubsection{Identifying perceived present focus}

In Section 6.2, we identified perceived time inconsistency by testing whether people value the noborrowing incentive more than they would if they perceived themselves to be time consistent. We now identify the perceived present focus parameter $\tilde{\beta}$ by putting more structure on that intuition.

As discussed in Section 6.2, risk-neutral people who perceive they are time consistent value the no-borrowing incentive at $w^{*}(b):=b-A B C D=b-b \frac{\tilde{\mu}(0)+\tilde{\mu}(b)}{2}$. The size of the behavior change premium trapezoid $A B E F$ depends on $\tilde{\beta}$. For an incentive of amount $b$, the difference between the desired and predicted demand curves is $(l+p+b)-\tilde{\beta}(l+p+b)=(1-\tilde{\beta})(l+p+b)$. Thus, the lengths of $\mathrm{AF}$ and $\mathrm{BE}$ are $(1-\tilde{\beta})(l+p+b)$ and $(1-\tilde{\beta})(l+p)$, respectively. The width of the trapezoid is the predicted change in borrowing probability induced by the incentive, $\tilde{\Delta}:=\tilde{\mu}(0)-\tilde{\mu}(b)$. Thus, the area of the trapezoid is $\tilde{\Delta}(1-\tilde{\beta})\left(l+p+\frac{b}{2}\right)$. The valuation of the incentive is thus 


$$
w(b)=b-A B C D+A B E F=\underbrace{b-b \frac{\tilde{\mu}(0)+\tilde{\mu}(b)}{2}}_{\text {valuation if time consistent }}+\underbrace{(1-\tilde{\beta})\left(l+p+\frac{b}{2}\right)}_{\text {internality reduction benefit }} \underbrace{\tilde{\Delta}}_{\begin{array}{c}
\text { perceived internality } \\
\text { pehavior change }
\end{array}} .
$$

We infer a lower $\tilde{\beta}$ (more perceived present focus) when $w$ is more positive (people are willing to pay more for the incentive to avoid future borrowing), adjusting for the valuation that a time-consistent person would have.

\subsection{Formal model with risk aversion}

We now formalize the model further and relax the risk neutrality assumption. Readers with less interest in these details can skip to the results in Section 7.4.

While the graphical exposition above assumed linear $\tilde{C}$, our formal results and parameter estimates use a quadratic approximation to $\tilde{C}(x)$. Let $\alpha:=\frac{\tilde{C}^{\prime \prime}(0)}{\tilde{C}^{\prime}(0)}$ be the coefficient of absolute risk aversion at $x=0$, and define $\rho:=\alpha(l+p)$. Under this quadratic approximation, $\rho$ approximates the percent difference in marginal utilities when people reborrow versus repay: $\rho \approx \tilde{C}^{\prime}(l+p) / \tilde{C}^{\prime}(0)-1$.

\subsubsection{Identifying sophistication versus naivete}

To identify sophistication while allowing for risk aversion under the quadratic approximation to $\tilde{C}$, we re-write Equation (3) as a function of $\alpha$ and $\rho$.

Proposition 1. Assume that terms of order $(l+p+b)^{3} \tilde{C}^{\prime \prime \prime}$ and $\tilde{\mu}^{\prime \prime} b^{2}$ are negligible. Then

$$
\underbrace{\beta(l+p)\left(1+\frac{\rho}{2}\right)}_{\text {period } 1 \text { self's reborrowing cost }}=\underbrace{\tilde{\beta}\left(l+p+b^{\dagger}\right)\left(1+\frac{\rho}{2}-\frac{\alpha}{2} b^{\dagger}\right)}_{\text {predicted reborrowing cost with incentive } b^{\dagger}},
$$

where $b^{\dagger}=\frac{100}{-\tilde{\Delta}}(\mu(0)-\tilde{\mu}(0))$.

\subsubsection{Identifying perceived present focus}

From the perspective of the period 0 self, the change in expected utility from a marginal change in $b($ at $w=0)$ is

$$
\frac{d V}{d b}=\delta^{2}[-\underbrace{(1-\tilde{\beta})(\tilde{C}(l+p)-\tilde{C}(-b))}_{\text {perceived internality }} \underbrace{\tilde{\mu}^{\prime}(b)}_{\text {behavior }}+\underbrace{(1-\tilde{\mu}(b)) \tilde{C}^{\prime}(-b)}_{\text {mechanical effect }}] .
$$

The two terms in Equation (7) generalize the graphical argument for the linear case. The first term, the product of the perceived internality and the predicted behavior change, corresponds to the behavior change premium trapezoid ABEF. The second term, the mechanical effect, corresponds 
to the valuation of a marginal incentive $d b$ for people who perceive themeselves to be time consistent. Mathematically, these follow from the Envelope Theorem arguments from Section 6.2.

Similar logic can be used to derive $\frac{d V}{d w}$. To compute the non-marginal effects of $w$ and $b$, we integrate over the marginal conditions and set them equal, giving an expression for the $w$ at which a person is indifferent between $w$ Money for Sure and the $\$ 100$ no-borrowing incentive. To obtain simple approximations to these integrals in terms of observables, we continue to assume that $\tilde{\mu}$ is locally linear and to take a quadratic approximation to $\tilde{C}$. This yields the following result.

Proposition 2. Assume that terms of order $(l+p)^{3} \tilde{C}^{\prime \prime \prime} / \tilde{C}^{\prime}$ are negligible and that $\tilde{\mu}$ is locally linear and separable in $w$ and $b$. If a borrower is indifferent between $w$ Money for Sure and a no-borrowing incentive $b$, then

$$
\begin{array}{r}
\left(1-\frac{\alpha w}{2}\right)\{\underbrace{w \cdot\left(1+\rho\left(\tilde{\mu}(0)+\frac{w \rho}{b} \frac{\tilde{\Delta}}{2}\right)\right)}_{\text {utility from } w \text { if time consistent }}-\underbrace{(1-\tilde{\beta})\left(1+\frac{\rho}{2}\right)(l+p)}_{\text {perceived internality }} \underbrace{\frac{w \rho}{b} \tilde{\Delta}}_{\text {behavior change }}\} \\
=\left(1-\frac{\alpha b}{2}\right)\{\underbrace{b \cdot\left(1-\tilde{\mu}(0)+\frac{\tilde{\Delta}}{2}\right)}_{\text {utility from b if time consistent }}+\underbrace{(1-\tilde{\beta})\left(1+\frac{\rho}{2}\right)\left(l+p+\frac{100}{2}\right)}_{\text {perceived internality }} \underbrace{\tilde{\Delta}}_{\text {behavior change }}\} .
\end{array}
$$

The left-hand side is the expected utility of $w$ dollars of Money for Sure, and the right-hand side is the expected utility of a no-borrowing incentive of $b$ dollars.

\subsubsection{Identifying curvature}

Our formulas can accommodate any curvature parameter $\alpha$. One approach is to use borrowers' certainty equivalents of the Flip a Coin for $\$ 100$ lottery: lower certainty equivalents imply more curvature. In Appendix E.3, we show that this implies a sample average $\alpha \approx 0.0064$.

The benefit of this approach is that $\alpha$ is elicited from our population of payday borrowers. Curvature estimates from other populations may not be relevant: the fact that payday borrowers carry very costly debt suggests that their marginal utility may be sensitive to small gains and losses. However, our estimated $\alpha \approx 0.0064$ may be too large: under a quadratic approximation, $\alpha \approx 0.0064$ implies that an extra $\$ 100$ of debt increases utility from the marginal dollar by 64 percent, and thus borrowers who have $\$ 400$ more debt (approximately the average loan size) in period 2 have 256 percent higher marginal utility. One potential reason why $\alpha \approx 0.0064$ may be an upper bound is that since the $\$ 100$ lottery is smaller than most loans, certainty equivalents may be affected by small-stakes risk aversion that is behaviorally distinct from utility function curvature (Rabin 2000). For comparison, our lottery $\alpha$ estimate is 3 to 30 times larger than other estimates using higher-stakes field decisions such as insurance choice and labor supply in less liquidity-constrained 
populations. ${ }^{28}$ In our empirical estimation, we therefore consider multiple curvature values between our estimated $\alpha \approx 0.0064$ and $\alpha=0$.

\subsection{Parameter estimates}

Propositions 1 and 2 provide equations that include only $\beta, \tilde{\beta}$, curvature parameters $\alpha$ and $\rho$, and observable data: loan sizes and fees, perceived and actual reborrowing probabilities, and valuations of the no-borrowing incentive. Appendix E.4 shows how these propositions can be re-arranged to provide estimating equations for sophistication $\beta / \tilde{\beta}$ and perceived present focus $\tilde{\beta}$. We then multiply the two to derive actual present focus: $(\beta / \tilde{\beta}) \times \tilde{\beta}=\beta$. With heterogeneity, our estimates are sample averages under certain orthogonality conditions. We estimate standard errors by bootstrapping.

Appendix E.5 considers other misprediction models, such as overoptimism about future repayment cost shocks. In a model where borrowers instead mistakenly perceive that future repayment costs will be share $\kappa$ as large as they actually are, $\beta / \tilde{\beta}$ can be re-interpreted as $\kappa$. If there are additional sources of misprediction besides naivete about present focus, $\beta / \tilde{\beta}$ is a lower bound on true sophistication, and $\beta$ is thus a lower bound on true present focus.

Table 3 presents our parameter estimates. The first five rows present estimates using the full sample at different values of $\alpha$, the curvature parameter for period 2 debt costs $\tilde{C}$. The estimates of $\beta / \tilde{\beta}, \tilde{\beta}$, and $\beta$ are monotonic in $\alpha$ over this range, so the estimates for $\alpha \approx 0.0064$ and $\alpha=0$ provide bounds. Our point estimates of borrowers' average $\beta / \tilde{\beta}$ range from 0.95 to 0.98 , reflecting the fact that the sample slightly underestimates borrowing on average. For each $\alpha, \beta / \tilde{\beta}$ is statistically distinguishable from one with slightly more than 95 percent confidence. Our point estimates of borrowers' average $\tilde{\beta}$ range from 0.76 to 0.87 , and the upper end of the confidence intervals never exceeds 0.90. Assuming less risk aversion increases $\tilde{\beta}$ because it increases the modeled valuation that a time-consistent borrower would have for the (risky) incentive, thereby reducing the premium attributed to perceived internality reduction. The point estimates of $\beta$ range from 0.74 to 0.83 .

The next two rows present estimates for the subsample of borrowers who had gotten three or fewer loans from the Lender in the six months before taking the survey, for the bounding high and low values of $\alpha$. The two rows after that present estimates for the complementary subsample with four or more loans of recent experience. Consistent with Figure 3, more experienced borrowers are fully sophisticated, with estimated $\beta / \tilde{\beta} \approx 1.00$, while less experienced borrowers have $\beta / \tilde{\beta}$ between 0.79 and 0.89 . The point estimates for $\tilde{\beta}$ differ modestly. Under the plausible assumption that $\beta \leq \tilde{\beta}$ for all borrowers, this implies that experienced borrowers are all sophisticated, although there is more scope for significant heterogeneity among the inexperienced borrowers.

\footnotetext{
${ }^{28}$ Using insurance decisions, Cohen and Einav (2007) estimate $\alpha \approx(0.00087,0.0019)$, Handel (2013) estimates $\alpha \approx(0.00019,0.000325)$, and Sydnor $(2010)$ estimates $\alpha \approx 0.002$. Chetty (2006) estimates a constant relative risk aversion coefficient of 0.7 from labor supply elasticities, which translates to $\alpha \approx 0.0007$ if payday borrowers have $\$ 1000$ monthly "uncommitted" (in the sense of Chetty and Szeidl, 2007) consumption. Using relatively small-stakes gambles, van Gaudecker, van Soest, and Wengstrom (2011) estimate $\alpha \approx 0.03$, and Holt and Laury (2002) estimate $\alpha \approx 0.2$.
} 
The estimates of $\beta$ are statistically different for the two groups, especially at the extreme assumption of $\alpha=0$. There are two possible explanations. First, it could be that the groups' actual $\beta$ parameters are the same, and the reduced misprediction in the experienced group is from learning about the utility cost of repayment, not learning about present focus. Second, the two groups might actually have different levels of present focus. Such differences could be driven by experiential learning in the sense of Laibson's (2018) "model-free equilibrium": borrowers with particularly low $\beta$ learn that borrowing is delivering low payoffs, and they thus avoid borrowing. In this model, borrowers do not necessarily learn an exact model of their preferences, and their perceived $\tilde{\beta}$ does not necessarily change - the low- $\beta$ types simply select out of borrowing.

As discussed in Appendix E.4, we estimate sample average parameters under certain orthogonality assumptions. The final rows of Table 3 present estimates where we separately estimate the parameters by above- versus below-median experience (our most important moderator) and take the subsample size-weighted average of the two estimates within each bootstrap replication. The resulting parameter estimates are almost identical to the primary estimates in the earlier rows. Thus, accounting for heterogeneity along this key dimension does not affect our estimates of the sample average.

The respondents to our expert survey believed that borrowers would have less demand for behavior change than they actually did. Only 56 percent believed that the average borrower would want motivation to avoid future borrowing. By contrast, Figure 7 documented that 90 percent of borrowers reported qualitatively that they wanted extra motivation to avoid payday loan debt. Quantitatively, Figure 10 shows that most respondents to our expert survey overestimated borrowers' average $\tilde{\beta}$. The average respondent predicted $\tilde{\beta} \approx 0.86$ (standard error $=0.03$ ), which is larger than the point estimates in Table 3 except at $\alpha=0$, the unrealistic risk-neutral case.

\section{WELFARE AND POLICY IMPLICATIONS}

In this section, we discuss the implications of our empirical results for consumer welfare and payday lending regulation. We consider three common regulations: a payday lending ban (in practice, effectuated by a low interest rate cap that causes all lenders to exit), a rollover restriction (in practice, effectuated by a required "cooling off period" that disallows additional borrowing for 30 days after three consecutive loans, as in the 2017 CFPB rule), and a loan size cap. We think of this section as only a first step, recognizing that other researchers could bring different lenses to the data.

Even this first step is potentially valuable, because there is substantial disagreement and uncertainty among experts about the welfare effects of regulation. Figure 11 shows that the experts we surveyed were divided about whether payday loan bans, cooling off periods, and loan size caps would benefit consumers. We also initiated a similar question about payday loan bans for the IGM Economic Experts Panel, a survey used to gauge opinion among leading economists. Of the IGM experts, 33 percent agreed that a payday loan ban would make consumers better off, while 25 
percent disagreed, and 37 percent were uncertain. ${ }^{29}$

Sub-sections 8.1, 8.2, 8.3, and 8.4 provide a graphical overview, theoretical results, numerical calibrations, and a discussion of caveats, respectively.

\subsection{Graphical overview}

We extend the model of present focus and naivete from Section 7 , slightly modifying the notation and re-numbering the periods. In period $t=0$, borrowers choose a loan amount $l$. In subsequent periods $t \geq 1$, borrowers choose whether to reborrow, repay, or default. The three periods from the estimation strategy in Section 7 could be any three periods in this section. We define $u(l)$ as the utility benefit of borrowing amount $l$ for a given borrower. $C(l)$ and $\tilde{C}(l)$ are now defined as the actual and perceived expected costs of repaying (or defaulting on) a loan of size $l$ starting in period 1, discounted to period 1 using the period 0 self's discount function. These expected costs are conditional on the period 0 information set about possible future liquidity and income shocks and the borrower's future behavior. Of course, $u(l), C(l)$, and the resulting choices and welfare will vary across borrowers.

We use the "long-run criterion," taking exponentially discounted utility to be normatively relevant. For our primary analyses, we follow Heidhues and Koszegi (2010) in assuming that the loan affects utility only after period $t=0$, as might be the case for a car repair that the borrower can afford only by taking out a loan. In this case, borrowers choose $l$ in $t=0$ to maximize $\beta \delta[u(l)-\tilde{C}(l)]$, and the welfare criterion is $\delta[u(l)-C(l)]$.

Figure 12 illustrates the loan size choice and resulting borrower welfare. Optimizing borrowers choose $l$ to equate marginal benefit $u^{\prime}(l)$ and actual marginal repayment $\operatorname{cost} C^{\prime}(l)$, giving loan size $l^{\dagger}$. The resulting welfare gain is the triangle $G$.

The two types of behavioral bias we have measured - time inconsistency and mispredictionboth reduce welfare. Present focus tempts people to delay repayment more than the period 0 self would like. This increases repayment costs $C(l)$ and reduces the resulting welfare gains $G$. If borrowers are sophisticated about present focus, they still correctly perceive repayment costs, so $\tilde{C}^{\prime}(l)=C^{\prime}(l)$. Thus, any loans that they take out must increase welfare, even if present focus reduces the possible gains.

If borrowers are naive about present focus or are otherwise overoptimistic about their likelihood of repayment, they will underestimate repayment costs. Overoptimistic borrowers would choose $l$ to equate $u^{\prime}(l)$ and perceived marginal repayment cost $\tilde{C}^{\prime}(l)$, giving loan size $l^{*}$ that exceeds the optimum $l^{\dagger}$. The resulting welfare loss from overborrowing is the triangle $L$.

In alternative analyses, we instead assume that the benefits of the loan accrue fully in $t=0$. In this case, borrowers maximize $u(l)-\beta \delta \tilde{C}(l)$, and the long-run welfare criterion is $u(l)-\delta C(l)$. This tempts people to overborrow relative to their long-run preferences, because they downweight repayment costs relative to utility benefits by an additional $\beta$. On the figure, this could be captured

\footnotetext{
${ }^{29}$ See here for the IGM survey results.
} 
by thinking of $C^{\prime}(l)$ as welfare-relevant repayment costs and $\tilde{C}^{\prime}(l)=\beta C^{\prime}(l)$ as the repayment costs as perceived by the period 0 decision-maker.

Of course, other behavioral biases could affect borrowing. For example, borrowing benefits $u(l)$ from payday loans might be misperceived if people are not fully aware of alternative forms of credit. In principle, shrouded fees could cause additional misperception of repayment $\operatorname{costs} C(l)$, although we argued in Section 3 that this is unlikely in the American payday lending market.

In any case, a payday loan ban increases consumer welfare if the welfare losses from overborrowing exceed the potential welfare gains from optimal borrowing, i.e. if $L>G$ on average across borrowers. The next two sub-sections provide theoretical and quantitative results exploring whether this might be the case. A key result is that for $\tilde{C}^{\prime}(l)$ and $C^{\prime}(l)$ to differ substantially, borrowers must be persistently naive. If borrowers are initially sophisticated or become sophisticated through experience, as suggested by our data, then $\tilde{C}^{\prime}(l)$ is probably close to $C^{\prime}(l), L$ is probably small relative to $G$, and a ban probably reduces consumer welfare in our model.

\subsection{Theoretical results}

\subsubsection{Formal setup}

In each period $t \geq 1$, borrowers receive a transitory shock $\theta_{t}$ and correlated shock $\eta_{t}$ and then have three options. First, they can repay $l+p(l)$. In this case, the game ends. Second, they can pay the fee $p(l)$ and reborrow the principal $l$. In this case, the game continues. Third, they can default, incurring immediate cost $\chi$. In this case, the game ends. We assume an infinite horizon, which allows us to consider stationary equilibria. For our theoretical results in this sub-section, we assume that the long-run discount factor is $\delta=1$, which is a close approximation given that pay cycles are two weeks to one month long.

The utility cost of repaying amount $x$ in period $t$ is now denoted $k\left(x, \theta_{t}, \eta_{t}\right)$. The perceived and actual repayment cost functions $\tilde{C}(l)$ and $C(l)$ are determined by borrower behavior in a perception-perfect equilibrium (O'Donoghue and Rabin 1999, 2001). Theorem 1 in Appendix F.1 shows that under certain regularity conditions, there exists a unique stationary equilibrium with smooth $\tilde{C}(l)$ and $C(l) .{ }^{30}$

To model learning, we assume that borrowers have perceived present focus $\tilde{\beta}_{0} \geq \beta$ before period $t^{\dagger}$ and $\tilde{\beta}_{1} \in\left[\beta, \tilde{\beta}_{0}\right]$ thereafter. For concreteness, we set $t^{\dagger}=1$ in the theory (but not the simulations); using a larger $t^{\dagger}$ would not affect our qualitative theoretical conclusions.

\subsubsection{Theoretical results on how present focus and naivete affect repayment costs and welfare}

The effect of $\beta$ and $\tilde{\beta}$ on repayment costs depends on the amount of volatility in repayment cost shocks $\{\theta, \eta\}$. Proposition 5 in Appendix F.3 shows that with high enough volatility, present focus

\footnotetext{
${ }^{30}$ We are able to establish these results even though the Bellman operator on the continuation value functions is not a contraction. With infinite horizon, there may also be non-stationary equilibria in environments with minimal variation in $\theta$ and $\eta$. We use stationarity as an equilibrium refinement.
} 
and naivete have zero effect on repayment costs: regardless of $\beta$ and $\tilde{\beta}$, borrowers repay in "good" states and reborrow in "bad" states. In Figure 12, this corresponds to the case where $\tilde{C}^{\prime}=C^{\prime}$, and $G>L=0$.

On the other hand, Proposition 6 in Appendix F.3 shows that in the limit case of vanishing volatility in $\theta$ and $\eta$, persistently naive $\left(\tilde{\beta}_{1}>\beta\right)$ borrowers perpetually reborrow because they are over-optimistic about repaying in the next period, which entices them to reborrow in the current period. This generates infinite repayment costs. In Figure 12, this corresponds to the case where $l^{*}>l^{\dagger}=0$ and $L=\infty$. However, this limit case corresponds to stark and counterfactual predictions. The main one is that with even small amounts of persistent naivete, borrowers would reborrow in perpetuity. However, this does not happen in the data. ${ }^{31}$

In fact, we can use observed reborrowing rates to provide upper bounds on the effects of $\beta$ and $\tilde{\beta}$ on repayment costs. The result below extends results such as those of O'Donoghue and Rabin $(1999,2001)$ to consider a setting with some uncertainty about the future costs of an action, thus providing a characterization of the welfare costs of present focus for a more realistic setting between the two extremes summarized above. To simplify exposition, we state the result below for the case where the probability of reborrowing does not vary with $\eta$, but we offer generalizations in the proof in Appendix F.6.

Proposition 3. Suppose that the unconditional distribution of $\eta$ is time invariant. Let $\mu$ be the empirically observed reborrowing rate. Relative to the repayment costs $C^{T C}(l)$ of time-consistent borrowers, the repayment costs $C_{\beta}^{S}(l)$ of borrowers with present focus $\beta$ and $\tilde{\beta}_{1}=\beta$ are bounded by

$$
C_{\beta}^{S}(l) \leq \frac{C^{T C}(l)}{1-(1-\beta) \mu} \leq \frac{C^{T C}(l)}{\beta} .
$$

If $\mu<1$, the repayment costs $C_{\beta, \tilde{\beta}_{1}}^{P N}(l)$ of partially naive borrowers with present focus $\beta$ and long-run beliefs $\tilde{\beta}_{1}>\beta$ are bounded by

$$
C_{\beta, \tilde{\beta}_{1}}^{P N}(l) \leq \frac{C^{T C}(l)-\mu \beta C_{\tilde{\beta}_{1}}^{S}(l)}{1-\mu} .
$$

The first expression shows that for sophisticates, present focus cannot increase repayment costs by more than proportion $1 / \beta$. The second expression shows that for persistently naive types, naivete can generate large repayment costs only in the limit of perpetual reborrowing $(\mu \rightarrow 1)$.

Proposition 3 has implications well beyond our setting, as it illustrates that theoretical results where minor naivete can have discontinuously large welfare costs (O'Donoghue and Rabin 1999, 2001; Heidhues and Koszegi 2009, 2010) hinge on the assumption of a deterministic environment. Indeed, proposition 4 in Appendix F.2 shows that in our model, behavior is continuous in all parameters in the presence of uncertainty. The proofs in Appendix F show that these results are

\footnotetext{
${ }^{31}$ Another counterfactual prediction is that because borrowers predict that their future selves will be approximately indifferent between reborrowing and repaying, they will believe that even small temporary incentives to repay next period will ensure repayment that period. However, our belief elicitations reject this.
} 
similar if borrowers mispredict future borrowing because they mispredict future repayment costs $k(x, \theta, \eta)$ rather than their level of present focus.

We can plug our parameter estimates from Section 7.4 into Proposition 3 to bound $\tilde{C} / C$, the proportion by which borrowers underestimate repayment costs. When the weak inequalities in Proposition 3 hold with equality, perceived costs are $\tilde{C}=\frac{C^{T C}}{1-\left(1-\tilde{\beta}_{0}\right) \mu}$, actual costs are $C=C_{\beta}^{S}=$ $\frac{C^{T C}}{1-(1-\beta) \mu}$, and the ratio is $\tilde{C} / C=\frac{1-(1-\beta) \mu}{1-\left(1-\tilde{\beta}_{0}\right) \mu}$. If the reborrowing probability is $\mu=0.75$ and if $\tilde{\beta}_{0}=0.78$ and $\beta=0.70$, as estimated in the sixth row of Table 3 , then $\tilde{C} \approx 1.20 C^{T C}, C \approx 1.29 C^{T C}$, and $\tilde{C} / C \approx 0.93$. That is, present focus increases repayment costs by 29 percent, and temporary naivete leads borrowers to underestimate these costs by 7 percent in period $t=0$. This suggests that even sizeable initial underestimation of future borrowing is not enough to generate a "debt trap" if borrowers learn over a borrowing spell. Alternatively, with persistent partial naivete matching the sample average estimates of $\tilde{\beta}$ and $\beta$, we have $\tilde{C} / C \approx 0.94$, so borrowers underestimate repayment costs by six percent. ${ }^{32}$

Even if $\tilde{C}^{\prime} / C^{\prime}=0.9$, which is conservative relative to the data-driven benchmarks in the previous paragraph, it is unlikely that $L>G$ in Figure 12 for many borrowers. In general, when demand for a product is only slightly distorted relative to the social optimum, the only way the product can reduce welfare is if consumers don't perceive much surplus from the product. In the context of Figure 12, when $\tilde{C}^{\prime} / C^{\prime}=0.9$, the only way to make $L$ larger than $G$ for a given loan size $l^{*}$ is to make both $u^{\prime}$ and $\tilde{C}^{\prime}$ very flat, so that $G$ becomes very short and $L$ becomes very wide. However, Appendix F.7 details two additional arguments that discipline how flat $u^{\prime}$ and $\tilde{C}^{\prime}$ can be. First, if consumers don't perceive much surplus from payday loans, demand would drop substantially if lenders charged even modestly higher fees. For example, assuming linear $u^{\prime}$ and $\tilde{C}^{\prime}$ and $\tilde{C}^{\prime} / C^{\prime}=0.9$, $L>G$ requires $u^{\prime}(0) / \tilde{C}^{\prime}(0) \leq 1.25$ : the marginal benefit of the first dollar borrowed must not exceed the perceived marginal cost of the first dollar borrowed by more than 25 percent. But empirical estimates such as Fekrazad (2020) suggest that demand is not so elastic. Second, an estimate of curvature disciplines how flat $\tilde{C}^{\prime}$ can be. For example, even assuming that $\tilde{C}^{\prime \prime} / \tilde{C}^{\prime}$ is more than ten times smaller than our lottery-based survey estimate of $\alpha$, we still have $G>L$ for most loans in our data.

\subsection{Numerical simulations}

\subsubsection{Summary of setup}

We now calibrate a parametric version of our borrowing and repayment model in order to evaluate payday lending regulations. We provide a brief summary here; Appendix G provides complete details.

\footnotetext{
${ }^{32}$ When the weak inequalities in Proposition 3 hold with equality, perceived costs are $\tilde{C}=C_{\tilde{\beta}_{1}}^{S}=\frac{C^{T C}(l)}{1-\left(1-\tilde{\beta}_{1}\right) \mu}$, actual costs are $C=C_{\beta, \tilde{\beta}_{1}}^{P N}=\frac{C^{T C}(l)-\mu \beta C_{\tilde{\beta}_{1}}^{S}(l)}{1-\mu}$, and the ratio is $\tilde{C} / C=\frac{1-\mu}{1-\mu+\left(\tilde{\beta}_{1}-\beta\right) \mu}$. If $\mu=0.75$ and if $\tilde{\beta}_{1}=0.76$ and $\beta=0.74$, as estimated in the top row of Table 3 for $\alpha=0.0064$, then $\tilde{C} / C \approx 0.94$.
} 
We assume a 15 percent borrowing fee, so $p(l) / l=0.15$. We set $\delta=0.998$, as this implies a five percent annual discount rate if a period is a two-week pay cycle. We assume that the utility benefit is $u(l, \nu)=\nu\left(1-e^{-\alpha_{0} l}\right)$, where $\alpha_{0}$ is the coefficient of absolute risk aversion and $\nu$ is a liquidity shock capturing variation in income or spending needs. The repayment cost is $k\left(x, \theta_{t}, \eta_{t}\right)=\left(\theta_{t}+\eta_{t}\right)\left(e^{\alpha_{1} x}-1\right)$, and the default cost is $\chi=\chi_{0}\left(e^{\alpha_{1}(l+p)}-1\right)$.

The welfare gains from borrowing are increasing in the slopes of $u^{\prime}$ and $C^{\prime}$, or equivalently the curvature of $u$ and $C$. We thus choose their curvature to be conservatively lower than the $\alpha \approx 0.0064$ estimated from valuations of the $\$ 100$ coin flip. We choose $(\beta, \tilde{\beta})=(0.74,0.77)$ from the row in Table 3 with $\alpha=0.002$, and we set $\alpha_{1}=0.002$, which correspondingly delivers $\tilde{C}(l)$ with $\alpha \approx 0.002$. We consider two cases for the curvature of $u(l)$ : higher demand elasticity $\left(\alpha_{0}=0.002\right)$ and lower demand elasticity $\left(\alpha_{0}=0.0002\right)$.

We calibrate the distributions of $\nu, \eta$, and $\theta$ to match the mean and variance of loan sizes and the probabilities of reborrowing and defaulting in the Lender's 2017 data. We assume a $\$ 500$ loan size cap at baseline, and we use data only from states with loan size caps between $\$ 450$ and $\$ 550$.

We consider a number of different alternatives to the baseline parametric assumptions made for the body of the paper, all of which are detailed in Appendix G.

\subsubsection{Results}

Table 4 presents simulated borrower behavior under the baseline policy, a $\$ 500$ loan size cap. Panels (a) and (b) present results for the higher and lower demand elasticity cases, respectively. Each row presents behavior under different assumptions for $\beta, \tilde{\beta}$, and whether the utility benefits of the loan $u(l)$ accrue in $t=0$ or $t=1$. Since the simulation parameters other than $\beta$ and $\tilde{\beta}$ were calibrated using our estimated $(\hat{\beta}, \hat{\tilde{\beta}})$ and then held constant across rows, the loan size and reborrowing probabilities in row 2 approximately match the empirical moments from Table A6, and they vary across the other rows.

In both panels, present focus parameters affect borrower behavior. Comparing rows 1 and 2 shows that borrowers with our primary estimates of $\beta$ and $\tilde{\beta}$ reborrow more and pay more back to the lender than they would if they were time consistent. Comparing rows 2 and 3 shows that people take out larger loans under the alternative assumption that the benefits of the loan accrue fully in $t=0$. Comparing row 5 to row 2 or row 6 shows that naivete increases reborrowing and amount repaid.

Row 7 considers borrowers who are partially naive in $t \leq 3$ but become sophisticated beginning in $t=4$, matching our empirical evidence. We estimate that $\beta / \tilde{\beta} \approx 0.84$ at $\alpha=0.002$ for borrowers with $0-3$ loans in the past six months. For this row, we maintain $\beta=0.74$ and set $\tilde{\beta}_{0}=\beta /(\beta / \tilde{\beta}) \approx 0.88$. This has little effect relative to row 2 .

Because misperceptions increase both the height and the width of the overborrowing loss triangle $L$ on Figure 12, the losses from overborrowing are proportional to the square of misperceptions. Thus, Jensen's Inequality implies that assuming homogeneous $\beta$ and $\tilde{\beta}$ causes us to understate welfare losses from overborrowing relative to a heterogeneous case with the same population average 
parameters. To address this, rows 4 and 8 consider extreme parameterizations of heterogeneity, where half the population is time consistent and the other half has $\beta$ and $\tilde{\beta}$ such that the population averages correspond to the assumptions in rows 2 and 7, respectively. Row 8 also imposes the alternative assumption that the benefits of the loan accrue fully in $t=0$, making this row a "worst-case scenario" for borrower welfare, and thus a "best-case scenario" for regulation.

In rows 9 and 10 , we set $\beta$ and $\tilde{\beta}$ to match expert forecasts. We use the $\tilde{\beta}=0.86$ forecasted by the average expert, and we calculate $\beta / \tilde{\beta}$ by inserting experts' average forecast of borrower misprediction into Equation (42) using $\alpha=0.002$. Multiplying these gives $\beta=0.63$. These assumptions generate much more reborrowing and much higher fees paid than the time-consistent case or our primary estimates.

Table 5 presents our model's welfare estimates under alternative payday lending regulations, using the same assumptions in each row as in Table 4. Panels (a) and (b) again present results for the higher and lower demand elasticity cases, respectively. In each cell of both panels, we present welfare as a percent of the welfare that time-consistent borrowers derive from the availability of payday loans with a $\$ 500$ loan size cap. Thus, we report $100 \%$ in column 1 (\$500 cap) of row 1 (time-consistent borrowers). Cells with positive values below $100 \%$ imply that borrowers still derive positive surplus from payday loans, but not as much as time-consistent consumers under a $\$ 500$ cap. Negative numbers would imply that borrowers are harmed by access to payday loans.

In each panel, column 1 presents welfare effects under the baseline policy, a $\$ 500$ loan size cap. Column 2 considers a $\$ 400$ loan size cap. On top of the baseline $\$ 500$ cap, column 3 adds a rollover restriction, which we model as a requirement that the loan be repaid no later than $t=3$. Modeling a payday loan ban requires some assumption about what alternative products borrowers can substitute to. Column 4 considers the effects of a payday loan ban under the assumption that borrowers can only substitute to higher-cost loans with a $\$ 500$ loan size cap and a 25 percent fee instead of 15 percent. Alternatively, a ban on all short-term high-cost borrowing would eliminate the surplus reported in column 1; this reduces welfare as long as the surplus in column 1 is positive. Of course, time-consistent borrowers are harmed by any regulation imposed in columns 2-4, although the rollover restriction does not affect them much because they repay quickly.

Comparing the different rows in column 1 of each panel, we can see the effects of different parameter assumptions on welfare under status quo regulation. Row 2 shows that the welfare losses from our estimated levels of present focus are only 4.1 percent with less elastic demand (Panel (a)) and 11.2 percent with more elastic demand (Panel (b)). In both panels, welfare is higher in row 2 than most subsequent rows, with heterogeneity, temporary naivete, and immediate utility benefits of the loan each eroding welfare somewhat relative to baseline. The larger welfare losses from present focus in Panel (b) are consistent with the discussion in Section 8.2 and Appendix F.7 about how more elastic demand decreases the gains from borrowing relative to the costs of overborrowing.

In the column 1 baseline, the welfare losses relative to the time-consistent case are less than 30 percent in each of the first eight rows, and the net benefits are always positive. This implies that a ban on all high-cost borrowing reduces welfare in our model. 
Welfare is lower when using experts' forecasts of $\beta$ and $\tilde{\beta}$ rows 9 and 10 . However, Table 4 shows that these scenarios generate counterfactually high reborrowing probabilities. When we instead recalibrate the distributions of $\theta$ and $\nu$ to match the empirical reborrowing rate at experts' $\beta$ and $\tilde{\beta}$, borrower welfare is much higher; see Tables A16-A19 in Appendix H. ${ }^{33}$

We can see the effects of different regulations by comparing the different columns in each row. Given that welfare is typically close to the time-consistent benchmark in column 1, it is not surprising that a tighter loan size cap (column 2) and a payday loan ban resulting in a higher 25 percent fee (column 4) both reduce welfare. However, adding a rollover restriction (column 3) at least slightly increases borrower welfare in all rows with time-inconsistent borrowers, as the rollover restriction induces faster repayment in line with long-run preferences.

Comparison to current regulation. Subject to the important caveats we discuss below, some current payday lending regulation reduces welfare in our model. Payday loan bans and tighter loan size caps both reduce welfare in our model. By contrast, 18 states have banned payday lending, and some states have particularly stringent loan size caps, such as the $\$ 300$ limit in California.

In our model, the only additional regulation that appears to benefit borrowers is a rollover restriction. This encourages faster repayment, consistent with our survey participants' qualitative and quantitative desires to motivate themselves to avoid reborrowing. By contrast, effective rollover restrictions are de facto much less common than bans and loan size caps because most de jure restrictions lack sufficiently long "cooling off periods" to prohibit new loans within the same pay cycle. However, the $2017 \mathrm{CFPB}$ rule includes a rollover restriction combined with a mandatory 30-day cooling off period after the third consecutive loan.

\subsection{Caveats}

We view this analysis as only an illustrative first step toward understanding the welfare effects of payday lending regulation. There are some important caveats.

First, our parameter estimates are local to the 1,205 people in our experiment, although our sample does not differ substantially on observables from the Lender's borrowers nationwide.

Second, our parameter estimates may also be sensitive to experimental design decisions, as discussed in Section 4.

Third, our welfare analyses take the long-run preferences of present-focused borrowers as being normatively relevant; this "long-run criterion" is common but somewhat controversial (Bernheim and Rangel 2009; Bernheim 2016; Bernheim and Taubinsky 2018). Using a different welfare criterion would likely strengthen our model's prediction that most regulation reduces welfare.

\footnotetext{
${ }^{33}$ Present focus and naivete have smaller effects on welfare (in Table 5) than they do on interest payments (in Table 4) for two reasons. First, while present focus and naivete can prolong borrowing spells and thus increase the monetary costs of borrowing, longer borrowing spells allow borrowers to repay when it is less costly to utility to do so. Second, borrowers in our model derive substantial surplus from payday loans: column 4 of Table 5 shows that the gains from borrowing are large even if fees increase substantially to 25 percent.
} 
Fourth, we model borrowing and repayment choices for an exogenous set of potential borrowing spells with exogenous initial liquidity demand, instead of modeling individuals who choose when to borrow over their lifetimes. As a result, we do not capture the possibility that rollover restrictions might result in more potential borrowing spells by breaking up single long spells into multiple short spells, or that people might keep larger buffer stocks in response to payday borrowing restrictions. However, additional analyses provide no empirical support for the latter concern: Appendix Table A5 shows that in the Panel Survey of Income Dynamics, households do not hold more liquid assets in states with payday loan bans or in years after their state imposes a ban.

Fifth, our analyses assume that there are no market failures or behavioral biases other than present focus and misprediction. For example, we do not consider market power or the potential effects of regulation on lender profits, although Section 3 argued that payday lending has the hallmarks of a relatively competitive market. We also do not consider the possibility that borrowers might overestimate the benefits of payday lending because they are not fully aware of cheaper sources of credit, such as credit cards. Agarwal, Skiba, and Tobacman (2009) find that some payday borrowers have access to cheaper credit, although Bhutta, Skiba, and Tobacman (2015) find that the amount of available credit is quite limited, and they argue that the Agarwal, Skiba, and Tobacman (2009) findings may have limited generalizability.

Sixth, our results about the welfare benefits of payday lending consider markets with existing regulations such as moderate loan size caps and truth-in-lending requirements, and thus do not speak to the effects of deregulation.

Seventh, our structural model assumes that if people reborrow, they must reborrow the same amount as their initial loan. As discussed in Sections 3 and 7.1, this assumption seems to be a reasonable approximation.

Finally, our results on learning are limited: we have only cross-sectional (not experimental or quasi-experimental) variation in experience, and our data include only six months of prior borrowing.

\section{CONCLUSION}

This paper contributes new empirical facts and theoretically grounded policy analysis to the contentious debate about payday lending regulation. We find that experience matters: inexperienced borrowers underestimate their likelihood of borrowing, while more experienced borrowers predict correctly. One natural explanation is that payday lending is a high-stakes setting with regular and repeated opportunities to observe one's behavior. We also find that borrowers are willing to pay a premium for an incentive to avoid future borrowing, which implies that they perceive themselves

to be time inconsistent. Our novel approach to estimating $\beta$ and $\tilde{\beta}$ in a dynamic stochastic setting could be useful in other applications.

In the context of our structural model of borrowing and repayment, our finding of present focus with limited naivete implies that payday loan bans and tightened loan size caps are likely to harm 
borrowers. Rollover restrictions could increase welfare by inducing faster repayment in line with long-run preferences. The disagreement and uncertainty among experts and regulators highlights the potential value of additional work carrying out behavioral welfare analyses grounded in theory and data.

An additional consideration is that even if borrowers' decisions are close to optimal given their liquidity needs, as our results suggest, the initial liquidity needs that drive people to demand payday loans may still be due to suboptimal consumption and savings decisions (e.g., Leary and Wang 2016). Policies and financial products that encourage more precautionary saving might therefore increase welfare. Bridging analyses like ours with a broader view of consumer decision making is an important next step for researchers and policymakers. 


\section{References}

Abaluck, Jason and Jonathan Gruber. 2011. "Choice Inconsistencies among the Elderly: Evidence from Plan Choice in the Medicare Part D Program." American Economic Review 101 (4):1180-1210.

Acland, Dan and Matthew R. Levy. 2012. "Naivete, Projection Bias, and Habit Formation in Gym Attendance." Working Paper: GSPP13-002.

. 2015. "Naiveté, Projection Bias, and Habit Formation in Gym Attendance." Management Science 61 (1):146-160.

Agarwal, Sumit, Paige Marta Skiba, and Jeremy Tobacman. 2009. "Payday Loans and Credit Cards: New Liquidity and Credit Scoring Puzzles?" American Economic Revew: Papers and Proceedings 99 (2):412417 .

Ali, S. Nageeb. 2011. "Learning Self-Control." Quarterly Journal of Economics 126 (2):857-893.

Allcott, Hunt, Matthew Gentzkow, and Lena Song. 2021. "Digital Addiction." Working Paper.

Allcott, Hunt, Benjamin Lockwood, and Dmitry Taubinsky. 2019. "Regressive Sin Taxes, with an Application to the Optimal Soda Tax." Quarterly Journal of Economics 134 (3):1557-1626.

Allcott, Hunt and Dmitry Taubinsky. 2015. "Evaluating Behaviorally Motivated Policy: Experimental Evidence from the Lightbulb Market." American Economic Review 105 (8):2501-2538.

Andreoni, James and Charles Sprenger. 2012a. "Estimating Time Preferences from Convex Budgets." American Economic Review 102 (7):3333-3356.

. 2012b. "Risk Preferences Are Not Time Preferences." American Economic Review 102 (7):33573376.

Ashraf, Nava, Dean Karlan, and Wesley Yin. 2006. "Tying Odysseus to the Mast: Evidence from a Commitment Savings Product in the Philippines." Quarterly Journal of Economics 121 (2):673-697.

Augenblick, Ned. 2018. "Short-Term Discounting of Unpleasant Tasks." Working Paper.

Augenblick, Ned, Muriel Niederle, and Charles Sprenger. 2015. "Working Over Time: Dynamic Inconsistency In Real Effort Tasks." Quarterly Journal of Economics 130 (3):1067-1115.

Augenblick, Ned and Matthew Rabin. 2019. "An Experiment on Time Preference and Misprediction in Unpleasant Tasks." Review of Economic Studies 86 (3):941-975.

Bai, Liag, Benjamin Handel, Edward Miguel, and Gautam Rao. 2018. "Self-Control and Demand for Preventive Health: Evidence from Hypertension in India." NBER Working Paper No. 23727.

Bernheim, B. Douglas. 2016. "The Good, the Bad, and the Ugly: A Unified Approach to Behavioral Welfare Economics." Journal of Benefit-Cost Analysis 7 (1):12-68.

Bernheim, B. Douglas and Antonio Rangel. 2009. "Beyond Revealed Preference: Choice-Theoretic Foundations for Behavioral Welfare Economics." Quarterly Journal of Economics 124 (1):51-104.

Bernheim, B. Douglas and Dmitry Taubinsky. 2018. Behavorial Public Economics, vol. 1, chap. 5. Elsevier, 1 ed.

Bertrand, Marianne and Adair Morse. 2011. "Information Disclosure, Cognitive Biases, and Payday Borrowing." Journal of Finance 66 (6):1865-1893.

Beshears, John, James J. Choi, Christopher Harris, David Laibson, Brigitte C. Madrian, and Jung Sakong. 2015. "Self-Control and Commitment: Can Decreasing the Liquidity of a Savings Account Increase Deposits?" Working Paper: NBER WP No. 21474. 
Bhutta, Neil, Jacob Goldin, and Tatiana Homonoff. 2016. "Consumer Borrowing after Payday Loan Bans." Journal of Law and Economics 59 (1):225-259.

Bhutta, Neil, Paige Marta Skiba, and Jeremy Tobacman. 2015. "Payday Loan Choices and Consequences." Journal of Money, Credit and Banking 47:223-260.

Bronnenberg, Bart J., Jean-Pierre Dube, Matthew Gentzkow, and Jesse M. Shapiro. 2015. "Do Pharmacists Buy Bayer? Informed Shoppers and the Brand Premium." Quarterly Journal of Economics 130 (4):16691729 .

Browning, Martin and Jeremy Tobacman. 2015. "Discounting and Optimism Equivalences." Working Paper.

Burke, Kathleen, Jesse Leary, and Jialan Wang. 2016. "Information Disclosure and Payday Lending in Texas." Working Paper.

Carrell, Scott and Jonathan Zinman. 2014. "In Harm's Way? Payday Loan Access and Military Personnel Performance." Review of Financial Studies 27 (9):2805-2840.

Carrera, Mariana, Heather Royer, Mark Stehr, Justin Sydnor, and Dmitry Taubinsky. 2021. "Who Chooses Commitment? Evidence and Welfare Implications." Working Paper.

Carter, Susan Payne, Kuan Liu, Paige Marta Skiba, and Justin Sydnor. 2019. "Time to Repay or Time to Delay? The Effect of Having More Time Before a Payday Loan is Due." Working Paper.

Carter, Susan Payne and William Skimmyhorn. 2017. "Much Ado About Nothing? New Evidence on the Effects of Payday Lending on Military Members." Review of Economics and Statistics 99 (4):606-621.

Carvalho, Leandro, Arna Olafsson, and Dan Silverman. 2019. "Misfortune and Mistake: The Financial Conditions and Decision-Making of High-Cost Loan Borrowers." Working Paper.

CFA. 2019. "Legal Status of Payday Loans by State." URL https://paydayloaninfo.org/stateinformation.

CFPB. 2016. "Payday Loans, Auto Title Loans, and High-Cost Installment Loans: Highlights from CFPB Research." Tech. rep., Consumer Financial Protection Bureau.

2017. "CFPB Finalizes Rule To Stop Payday Debt Traps." URL https:// www.consumerfinance.gov/about-us/newsroom/cfpb-finalizes-rule-stop-payday-debt-traps/.

Chaloupka, Frank J., Matthew R. Levy, and Justin S. White. 2019. "Estimating Biases in Smoking Cessation: Evidence from a Field Experiment." Working Paper: NBER WP No. 26522.

Chetty, Raj. 2006. "A New Method of Estimating Risk Aversion." American Economic Review 96 (5):18211834.

Chetty, Raj, Adam Looney, and Kory Kroft. 2009. "Salience and Taxation: Theory and Evidence." American Economic Review 99 (4):1145-1177.

Chetty, Raj and Adam Szeidl. 2007. "Consumption Commitments and Risk Preferences." Quarterly Journal of Economics 122 (2):831-877.

Cohen, Alma and Liran Einav. 2007. "Estimating Risk Preferences from Deductible Choice." American Economic Review 97 (3):745-788.

DellaVigna, Stefano and Ulrike Malmendier. 2004. "Contract Design and Self-Control: Theory and Evidence." Quarterly Journal of Economics 119 (2):353-402.

—. 2006. "Paying Not to Go to the Gym." American Economic Review 96 (3):694-719. 
DellaVigna, Stefano and Devin Pope. 2018. "Predicting Experimental Results: Who Knows What?" Journal of Political Economy 126 (6).

Dobbie, Will and Paige Marta Skiba. 2013. "Information Asymmetries in Consumer Credit Markets: Evidence from Payday Lending." American Economic Journal: Applied Economics 5 (4):256-282.

Duflo, Esther, Michael Kremer, and Jonathan Robinson. 2011. "Nudging Farmers to Use Fertilizer: Theory and Experimental Evidence from Kenya." American Economic Review 101 (6):2350-2390.

Ericson, Keith. 2011. "Forgetting We Forget: Overconfidence and Memory." Journal of the European Economic Association 9 (1):43-60.

Ericson, Keith Marzilli and David Laibson. 2019. Intertemporal Choice, vol. 2, chap. 1. Elsevier, 1 ed.

Ernst\&Young. 2009. "The Cost of Providing Payday Loans in a US Multiline Operator Environment." Tech. rep., Ernst \& Young LLP.

Evans, Tim. 2019. "Will Indiana payday loan rates remain above state's 'loan shark' threshold?"

Fang, Hanming and Dan Silverman. 2004. "Time Inconsistency and Welfare Program Participation: Evidence from the NLSY." Cowles Foundation Discussion Paper No. 1465.

Fekrazad, Amir. 2020. "Impacts of interest rate caps on the payday loan market: Evidence from Rhode Island." Journal of Banking and Finance 105 (105750):1-31.

Gabaix, Xavier. 2017. "Behavioral Macroeconomics Via Sparse Dynamic Programming." Working Paper: NBER WP No. 21848.

Gagnon-Bartsch, Tristan, Matthew Rabin, and Joshua Schwartzstein. 2019. "Channeled Attention and Stable Errors." Working Paper: HBS WP 18-108.

Gathergood, John, Benedict Guttman-Kenney, and Stefan Hunt. 2019. "How Do Payday Loans Affect Borrowers? Evidence from the U.K. Market." Review of Financial Studies 32 (2):496-523.

Gine, Xavier, Dean Karlan, and Jonathan Zinman. 2010. "Put Your Money Where Your Butt Is: A Commitment Contract for Smoking Cessation." American Economic Journal: Applied Economics 2:213-235.

Goda, Gopi Shah, Matthew R. Levy, Colleen Flaherty Manchester, Aaron Sojourner, and Joshua Tasoff. 2015. "The Role of Time Preferences and Exponential-Growth Bias in Retirement Savings." Working Paper: NBER WP No. 21482.

Grubb, Michael D. and Matthew Osborne. 2015. "Cellular Service Demand: Biased Beliefs, Learning, and Bill Shock." American Economic Review 105 (1):234-271.

Handel, Benjamin. 2013. "Adverse Selection and Inertia in Health Insurance Markets: When Nudging Hurts." American Economic Review 103 (7):2643-2682.

Handel, Benjamin and Jonathan T. Kolstad. 2015. "Health Insurance for "Humans": Information Frictions, Plan Choice, and Consumer Welfare." American Economic Review 105 (8):2449-2500.

Handel, Benjamin, Jonathan T. Kolstad, and Johannes Spinnewijn. 2019. "Information Frictions and Adverse Selection: Policy Interventions in Health Insurance Markets." Review of Economics and Statistics 101 (2):326-340.

Harris, Cristopher and David Laibson. 2001. "Dynamic Choices of Hyberbolic Conusmers." Econometrica 69 (4):935-957.

Heidhues, Paul and Botond Köszegi. 2009. "Futile Attempts at Self-Control." Journal of the European Economic Association 7 (2):423-434. URL https://academic.oup.com/jeea/article-lookup/doi/ 10.1162/JEEA.2009.7.2-3.423. 
Heidhues, Paul and Botond Koszegi. 2010. "Exploiting Naïvete about Self-Control in the Credit Market." American Economic Review 100:2279-2303.

Heidhues, Paul and Philipp Strack. forthcoming. "Identifying Procrastination from the Timing of Choices." American Economic Review .

Holt, Charles A. and Susan K. Laury. 2002. "Risk Aversion and Incentive Effects." American Economic Review 92 (5):1644-1655.

John, Anett. 2020. "When Commitment Fails - Evidence from a Field Experiment." Management Science $66(2)$.

Karlan, Dean, Maggie McConnell, Sendhil Mullainathan, and Jonathan Zinman. 2016. "Getting to the Top of the Mind: How Reminders Increase Savings." Management Science 62 (12).

Kaur, Supreet, Michael Kremer, and Sendhil Mullainathan. 2015. "Self-Control at Work." Journal of Political Economy 123 (6):1227-1277.

Knight, Thaya Brook. 2017. "This Government Agency Is Seriously Overstepping Its Bounds." URL https://www.cato.org/publications/commentary/government-agency-seriously-oversteppingits-bounds.

Kuchler, Theresa and Michaela Pagel. 2018. "Sticking to Your Plan: The Role of Present Bias for Credit Card Paydown." Working Paper: NBER WP No. 24881.

Laibson, David. 1997. "Golden Eggs and Hyperbolic Discounting." Quarterly Journal of Economics $112(2): 443-478$.

. 2015. "Why Don't Present-Baised Agents Make Commitments?" American Economic Review 105 (5):267-272.

—. 2018. "Private Paternalism, the Commitment Puzzle, and Model-Free Equilibrum." AEA Papers and Proceedings 108:1-21.

Laibson, David, Peter Maxted, Andrea Repetto, and Jeremy Tobacman. 2015. "Estimating Discount Functions with Consumption Choices over the Lifecycle." Working Paper.

Leary, Jesse and Jialan Wang. 2016. "Liquidity Constraints and Budgeting Mistakes: Evidence from Social Security Recipients." Working Paper.

Mahajan, Aprajit, Christian Michel, and Alessandro Tarozzi. 2020. "Identification of Time-Inconsistent Models: The Case of Insecticide Treated Nets." Working Paper: NBER WP No. 27198.

Mann, Robert. 2013. "Assessing the Optimism of Payday Loan Borrowers." Supreme Court Economic Review 21 (1):105-132.

Martinez, Seung-Keun, Stephan Meier, and Charles Sprenger. 2020. "Taxes and Procrastination: Evidence from Boston Tax-Filers." Working Paper.

Melzer, Brian T. 2011. "The Real Costs of Credit Access: Evidence from the Payday Lending Market." Quarterly Journal of Economics 126 (1):517-555.

—. 2018. "Spillovers from Costly Credit." Review of Financial Studies 31 (9):3568-3594.

Milgrom, Paul and Ilya Segal. 2002. "Envelope Theorems for Arbitrary Choice sets." Econometrica 70 (2):583-601.

Morgan, Donald P., Michael R. Strain, and Ihab Seblani. 2012. "How Payday Credit Access Affects Overdrafts and Other Outcomes." Journal of Money, Credit and Banking 44 (2-3):519-531. 
Morse, Adair. 2011. "Payday lenders: Heroes or villains?" Journal of Financial Economics 102 (1):28-44.

Mueller, Andreas I., Johannes Spinnewijn, and Giorgio Topa. 2019. "Job Seekers' Perceptions and Employment Prospects: Heterogeneity, Duration Dependence and Bias." Working Paper.

NCSL. 2019. "Payday Lending State Statutes." URL https://www.ncsl.org/research/financialservices-and-commerce/payday-lending-state-statutes.aspx.

O'Donoghue, Ted and Matthew Rabin. 1999. "Doing It Now or Later." American Economic Review 89 (1):103-124.

—. 2001. "Choice and Procrastination." Quarterly Journal of Economics 116 (1):121-160.

Paserman, M. Daniele. 2008. "Job Search and Hyperbolic Discounting: Structural Estimation and Policy Evaluation." Economic Journal 118:1418-1452.

Rabin, Matthew. 2000. "Risk Aversion and Expected-utility Theory: A Calibration Theorem." Econometrica $68(5): 1281-1292$.

Read, Danieal and Barbara van Leeuwen. 1998. "Predicting Hunger: The Effects of Appetite and Delay on Choice." Organizational Behavior and Human Decision Processes 76 (2):189-205.

Rees-Jones, Alex and Dmitry Taubinsky. Forthcoming. "Measuring Schmeduling." Review of Economic Studies.

Royer, Heather, Mark Stehr, and Justin Sydnor. 2015. "Incentives, Commitments, and Habit Formation in Exercise: Evidence from a Field Experiment with Workers at a Fortune-500 Company." American Economic Journal: Applied Economics 7 (3):51-84.

Sadoff, Sally, Anya Samek, and Charles Sprenger. Forthcoming. "Dynamic Inconsistency in Food Choice: Experimental Evidence from Two Food Deserts." Review of Economic Studies .

Schilbach, Frank. 2019. "Alcohol and Self-Control: A Field Experiment in India." American Economic Review 109 (4):1290-1322.

Shapiro, Jesse M. 2005. "Is there a daily discount rate? Evidence from the food stamp nutrition cycle." Journal of Public Economics 89:303-325.

Shui, Haiyan and Lawrence M. Ausubel. 2005. "Time Inconsistency in the Credit Card Market." Working Paper.

Skiba, Paige Marta and Jeremy Tobacman. 2018. "Payday Loans, Uncertainty, and Discounting: Explaining Patterns of Borrowing, Repayment, and Default." Working Paper.

—. 2019. "Do Payday Loans Cause Bankruptcy?" Journal of Law and Economics 62 (3):485-519.

Strack, Philipp and Dmitry Taubinsky. 2021. "Dynamic Preference "Reversals" and Time Inconsistency." working paper .

Taubinsky, Dmitry and Alex Rees-Jones. 2018. "Attention Variation and Welfare: Theory and Evidence from a Tax Salience Experiment." Review of Economic Studies 85 (4):2462-2496.

Toussaert, Severine. 2018. "Eliciting Temptation and Self-Control Through Menu Choices: A Lab Experiment." Econometrica 86 (3):859-889.

van Gaudecker, Hans-Martin, Arthur van Soest, and Erik Wengstrom. 2011. "Heterogeneity in Risky Choice Behavior in a Broad Population." American Economic Review 101 (2):664-694.

Wilson, Eric and Eva Wolkowitz. 2017. "2017 Financially Underserved Market Size Study.” Tech. rep., Center for Financial Services Innovation. 
Yaouanq, Yves Le and Peter Schwardmann. 2019. "Learning about one's self." Working Paper.

Zinman, Jonathan. 2010. "Restricting consumer credit access: Household survey evidence on effects around the Oregon rate cap." Journal of Banking and Finance 34 (3):546-556. 
Table 1: Descriptive Statistics and External Validity

\begin{tabular}{lccc}
\hline & $(1)$ & $(2)$ & $(3)$ \\
& $\begin{array}{c}\text { Valid } \\
\text { sample }\end{array}$ & $\begin{array}{c}\text { Customers on } \\
\text { survey days }\end{array}$ & $\begin{array}{c}2017 \text { loans } \\
\text { nationwide }\end{array}$ \\
\hline Loans in past six months & 5.35 & & 6.03 \\
& $(2.94)$ & & $(4.22)$ \\
Annual income $(\$ 000 s)$ & 34.0 & 31.8 & 28.9 \\
& $(21.1)$ & $(21.3)$ & $(38.0)$ \\
Internal credit score & 862 & 870 & 861 \\
& $(122)$ & $(193)$ & $(125)$ \\
Pay cycle length (days) & 16.0 & 18.1 & 17.3 \\
& $(7.7)$ & $(9.1)$ & $(8.2)$ \\
Loan length $($ days $)$ & 17.3 & 18.7 & 17.5 \\
& $(5.9)$ & $(6.8)$ & $(8.4)$ \\
Loan amount $(\$)$ & 373 & 359 & 366 \\
& $(161)$ & $(165)$ & $(166)$ \\
\hline $\mathrm{N}$ & 1,205 & 13,191 & 33,194 \\
\hline
\end{tabular}

Notes: This table presents the means (with standard deviations in parentheses) of key variables in data from the Lender. "Customers on survey days" means all customers who got a loan from a Lender's store on a day when the survey was available in that store. "2017 loans nationwide" is a random sample of people who took out a payday loan from the Lender in 2017. Loans in past six months is not available for all customers on survey days. 
Table 2: Misprediction and Behavior Change Premium by Experience

\begin{tabular}{|c|c|c|c|c|c|c|c|c|}
\hline & \multicolumn{4}{|c|}{ Misprediction (percent) } & \multicolumn{4}{|c|}{ Behavior change premium $(\$)$} \\
\hline & (1) & $(2)$ & (3) & (4) & (5) & $(6)$ & $(7)$ & $(8)$ \\
\hline Loans in past six months & $\begin{array}{l}-2.74 \\
(0.68)\end{array}$ & $\begin{array}{l}-2.23 \\
(0.71)\end{array}$ & & & $\begin{array}{l}1.09 \\
(0.38)\end{array}$ & $\begin{array}{c}1.13 \\
(0.39)\end{array}$ & & \\
\hline Loans in current spell & & & $\begin{array}{l}-2.69 \\
(0.68)\end{array}$ & $\begin{array}{l}-2.23 \\
(0.71)\end{array}$ & & & $\begin{array}{c}0.98 \\
(0.38)\end{array}$ & $\begin{array}{c}1.11 \\
(0.38)\end{array}$ \\
\hline Loans before current spell & & & $\begin{array}{l}-3.34 \\
(1.17)\end{array}$ & $\begin{array}{l}-2.18 \\
(1.25)\end{array}$ & & & $\begin{array}{c}2.92 \\
(0.71)\end{array}$ & $\begin{array}{c}3.01 \\
(0.75)\end{array}$ \\
\hline $\begin{array}{l}\text { High predicted } \\
\text { demand response }\end{array}$ & & & & & $\begin{array}{l}13.45 \\
(2.24)\end{array}$ & $\begin{array}{l}12.00 \\
(2.24)\end{array}$ & $\begin{array}{l}13.23 \\
(2.23)\end{array}$ & $\begin{array}{l}12.04 \\
(2.23)\end{array}$ \\
\hline Observations & 633 & 633 & 633 & 633 & 1,205 & 1,205 & 1,205 & 1,205 \\
\hline $\begin{array}{l}\text { Controls } \\
\text { p-value (current }=\text { before) }\end{array}$ & No & Yes & $\begin{array}{c}\text { No } \\
0.526\end{array}$ & $\begin{array}{c}\text { Yes } \\
0.959\end{array}$ & No & Yes & $\begin{array}{c}\text { No } \\
0.002\end{array}$ & $\begin{array}{c}\text { Yes } \\
0.003\end{array}$ \\
\hline
\end{tabular}

Notes: Columns 1-4 present regressions of misprediction $R_{i}-\tilde{\mu}_{i}(0)$ on the reported covariates, where $R_{i}$ is an indicator for whether person $i$ got another payday loan in the next eight weeks. Columns $5-8$ present regressions of the behavior change premium $w(100)_{i}-w^{*}(100)_{i}$ on the reported covariates, where $w(100)_{i}$ is person $i$ 's valuation of the $\$ 100$ no-borrowing incentive and $w^{*}(100)_{i}:=100-100 \frac{\tilde{\mu}(0)_{i}+\tilde{\mu}(100)_{i}}{2}$ is the modeled valuation of the $\$ 100$ no-borrowing incentive if person $i$ were risk-neutral and time consistent. Columns $1-4$ include only the Control group, while columns 5-8 include all participants with valid survey data. "High predicted demand response" is an indicator for people who reported that they would have a lower borrowing probability with the incentive compared to without. "Controls" are annual income, internal credit score, pay cycle length, loan length, loan amount, took survey in store, and valuation of coin flip. Robust standard errors are in parentheses. 
Table 3: Partially Naive Present Focus Parameters

\begin{tabular}{|c|c|c|c|c|}
\hline & $\alpha$ & $\begin{array}{c}(1) \\
\text { Estimated } \beta / \tilde{\beta}\end{array}$ & $\begin{array}{c}(2) \\
\text { Estimated } \tilde{\beta}\end{array}$ & $\begin{array}{c}(3) \\
\text { Estimated } \beta\end{array}$ \\
\hline Full sample & 0.0064 & $\begin{array}{c}0.98 \\
(0.95,0.99)\end{array}$ & $\begin{array}{c}0.76 \\
(0.73,0.78)\end{array}$ & $\begin{array}{c}0.74 \\
(0.71,0.77)\end{array}$ \\
\hline Full sample & 0.002 & $\begin{array}{c}0.96 \\
(0.93,0.99)\end{array}$ & $\begin{array}{c}0.77 \\
(0.74,0.79)\end{array}$ & $\begin{array}{c}0.74 \\
(0.70,0.77)\end{array}$ \\
\hline Full sample & 0.0005 & $\begin{array}{c}0.95 \\
(0.91,1.00)\end{array}$ & $\begin{array}{c}0.83 \\
(0.80,0.85)\end{array}$ & $\begin{array}{c}0.79 \\
(0.75,0.83)\end{array}$ \\
\hline Full sample & 0.0002 & $\begin{array}{c}0.95 \\
(0.90,0.99)\end{array}$ & $\begin{array}{c}0.85 \\
(0.83,0.88)\end{array}$ & $\begin{array}{c}0.81 \\
(0.77,0.85)\end{array}$ \\
\hline Full sample & 0 & $\begin{array}{c}0.95 \\
(0.90,0.99)\end{array}$ & $\begin{array}{c}0.87 \\
(0.85,0.90)\end{array}$ & $\begin{array}{c}0.83 \\
(0.78,0.87)\end{array}$ \\
\hline $0-3$ loans in past six months & 0.0064 & $\begin{array}{c}0.89 \\
(0.71,0.94)\end{array}$ & $\begin{array}{c}0.78 \\
(0.74,0.82)\end{array}$ & $\begin{array}{c}0.70 \\
(0.52,0.75)\end{array}$ \\
\hline $0-3$ loans in past six months & 0 & $\begin{array}{c}0.79 \\
(0.59,0.91)\end{array}$ & $\begin{array}{c}0.92 \\
(0.87,0.97)\end{array}$ & $\begin{array}{c}0.73 \\
(0.54,0.85)\end{array}$ \\
\hline $4+$ loans in past six months & 0.0064 & $\begin{array}{c}1.00 \\
(0.97,1.01)\end{array}$ & $\begin{array}{c}0.75 \\
(0.72,0.78)\end{array}$ & $\begin{array}{c}0.75 \\
(0.71,0.77)\end{array}$ \\
\hline $4+$ loans in past six months & 0 & $\begin{array}{c}1.00 \\
(0.95,1.05)\end{array}$ & $\begin{array}{c}0.86 \\
(0.83,0.89)\end{array}$ & $\begin{array}{c}0.86 \\
(0.80,0.90)\end{array}$ \\
\hline Group by loans in past six months & 0.0064 & $\begin{array}{c}0.96 \\
(0.90,0.98)\end{array}$ & $\begin{array}{c}0.76 \\
(0.73,0.78)\end{array}$ & $\begin{array}{c}0.73 \\
(0.68,0.75)\end{array}$ \\
\hline Group by loans in past six months & 0 & $\begin{array}{c}0.94 \\
(0.86,0.98)\end{array}$ & $\begin{array}{c}0.87 \\
(0.85,0.90)\end{array}$ & $\begin{array}{c}0.82 \\
(0.75,0.86)\end{array}$ \\
\hline
\end{tabular}

Notes: This table presents estimates of sophistication $\beta / \tilde{\beta}$, perceived present focus $\tilde{\beta}$, and actual present focus $\beta$ for different values of the coefficient of absolute risk aversion $\alpha$, using equations derived in Appendix E. 4 from Propositions 1 and 2. The bottom two rows define groups of observations for estimation using both loan size and above/below median loans in past six months. 95 percent confidence intervals calculated using the bias-corrected percentile bootstrap are in parentheses. 


\section{Table 4: Simulated Borrower Behavior}

(a) Higher Demand Elasticity

\begin{tabular}{llccc}
\hline Row & Scenario & $\begin{array}{c}(1) \\
\text { Average } \\
\text { loan size }\end{array}$ & $\begin{array}{c}(2) \\
\text { Probability of } \\
\text { reborrowing }\end{array}$ & $\begin{array}{c}(3) \\
\text { Average } \\
\text { amount repaid }\end{array}$ \\
\hline 1 & $\beta=1, \tilde{\beta}=1$ & 403 & 0.42 & 488 \\
2 & $\beta=0.74, \tilde{\beta}=0.77$ (primary estimates) & 394 & 0.78 & 610 \\
3 & $\beta=0.74, \tilde{\beta}=0.77$, consume in $t=0$ & 426 & 0.79 & 666 \\
4 & Heterogeneous & 386 & 0.66 & 665 \\
5 & $\beta=0.74, \tilde{\beta}=1$ & 403 & 0.85 & 724 \\
6 & $\beta=0.74, \tilde{\beta}=0.74$ & 391 & 0.76 & 592 \\
7 & $\beta=0.74, \tilde{\beta}=0.88, \tilde{\beta}=0.74$ (learning) & 400 & 0.83 & 686 \\
8 & Primary, heterogeneous, learning, consume in $t=0$ & 423 & 0.68 & 944 \\
9 & $\beta=0.63, \tilde{\beta}=0.86$ (expert forecast) & 400 & 0.91 & 908 \\
10 & $\beta=0.63, \tilde{\beta}=0.86$, consume in $t=0$ & 445 & 0.91 & 1017 \\
\hline
\end{tabular}

(b) Lower Demand Elasticity

\begin{tabular}{llccc}
\hline Row & Scenario & $\begin{array}{c}(1) \\
\text { Average } \\
\text { loan size }\end{array}$ & $\begin{array}{c}(2) \\
\text { Probability of } \\
\text { reborrowing }\end{array}$ & $\begin{array}{c}(3) \\
\text { Average } \\
\text { amount repaid }\end{array}$ \\
\hline 1 & $\beta=1, \tilde{\beta}=1$ & 410 & 0.43 & 496 \\
2 & $\beta=0.74, \tilde{\beta}=0.77$ (primary estimates) & 393 & 0.78 & 610 \\
3 & $\beta=0.74, \tilde{\beta}=0.77$, consume in $t=0$ & 445 & 0.79 & 700 \\
4 & Heterogeneous & 379 & 0.67 & 644 \\
5 & $\beta=0.74, \tilde{\beta}=1$ & 410 & 0.85 & 737 \\
6 & $\beta=0.74, \tilde{\beta}=0.74$ & 389 & 0.76 & 589 \\
7 & $\beta=0.74, \tilde{\beta}=0.88, \tilde{\beta}=0.74$ (learning) & 405 & 0.83 & 694 \\
8 & Primary, heterogeneous, learning, consume in $t=0$ & 438 & 0.69 & 990 \\
9 & $\beta=0.63, \tilde{\beta}=0.86$ (expert forecast) & 403 & 0.91 & 917 \\
10 & $\beta=0.63, \tilde{\beta}=0.86$, consume in $t=0$ & 470 & 0.91 & 1079 \\
\hline
\end{tabular}

Notes: Panels (a) and (b) are calibrated assuming borrowers have higher and lower demand elasticities, respectively. Panel (a) assumes that $\alpha_{0}=0.002$. Panel (b) assumes that $\alpha_{0}=0.0002$. Rows 3 and 8 present alternative analyses where the benefits of the loan accrue fully in $t=0$, so borrowers overborrow relative to the welfare criterion. Rows 4 and 8 model heterogeneity, where half the population is time consistent and the other half has $\beta$ and $\tilde{\beta}$ such that the population averages correspond to the assumptions in rows 2 and 7 , respectively. Row 7 models learning, assuming $\beta=0.74, \tilde{\beta}_{0}=0.88$ in periods $0 \leq t \leq 3$, and $\tilde{\beta}_{1}=\beta$ in periods $t \geq 4$. Rows 9 and 10 set $\beta$ and $\tilde{\beta}$ to match expert forecasts. 


\section{Table 5: Borrower Welfare Under Payday Lending Regulations}

(a) Higher Demand Elasticity

\begin{tabular}{|c|c|c|c|c|c|}
\hline Row & Scenario & $\begin{array}{c}(1) \\
\text { Baseline } \\
(\$ 500 \text { cap }) \\
\end{array}$ & $\begin{array}{l}(2) \\
\$ 400 \\
\text { cap }\end{array}$ & $\begin{array}{l}(3) \\
\text { Rollover } \\
\text { restriction }\end{array}$ & $\begin{array}{l}(4) \\
25 \% \\
\text { fee }\end{array}$ \\
\hline 1 & $\beta=1, \tilde{\beta}=1$ & $100.0 \%$ & $92.0 \%$ & $99.8 \%$ & $94.9 \%$ \\
\hline 2 & $\beta=0.74, \tilde{\beta}=0.77$ (primary estimates) & $95.9 \%$ & $88.7 \%$ & $97.4 \%$ & $90.3 \%$ \\
\hline 3 & $\beta=0.74, \tilde{\beta}=0.77$, consume in $t=0$ & $95.2 \%$ & $88.3 \%$ & $96.8 \%$ & $89.4 \%$ \\
\hline 4 & Heterogeneous & $90.8 \%$ & $84.4 \%$ & $97.3 \%$ & $84.4 \%$ \\
\hline 5 & $\beta=0.74, \tilde{\beta}=1$ & $91.1 \%$ & $84.8 \%$ & $97.1 \%$ & $84.5 \%$ \\
\hline 6 & $\beta=0.74, \tilde{\beta}=0.74$ & $96.7 \%$ & $89.3 \%$ & $97.4 \%$ & $91.2 \%$ \\
\hline 7 & $\beta=0.74, \tilde{\beta_{0}}=0.88, \tilde{\beta_{1}}=0.74$ (learning) & $95.1 \%$ & $88.0 \%$ & $97.2 \%$ & $88.8 \%$ \\
\hline 8 & Primary, heterogeneous, learning, consume in $t=0$ & $90.2 \%$ & $84.5 \%$ & $96.0 \%$ & $82.8 \%$ \\
\hline 9 & $\beta=0.63, \tilde{\beta}=0.86$ (expert forecast) & $80.8 \%$ & $76.4 \%$ & $95.8 \%$ & $71.8 \%$ \\
\hline 10 & $\beta=0.63, \tilde{\beta}=0.86$, consume in $t=0$ & $77.0 \%$ & $74.3 \%$ & $94.3 \%$ & $66.2 \%$ \\
\hline
\end{tabular}

(b) Lower Demand Elasticity

\begin{tabular}{|c|c|c|c|c|c|}
\hline Row & Scenario & $\begin{array}{c}(1) \\
\text { Baseline } \\
(\$ 500 \text { cap })\end{array}$ & $\begin{array}{c}(2) \\
\$ 400 \\
\text { cap }\end{array}$ & $\begin{array}{c}(3) \\
\text { Rollover } \\
\text { restriction }\end{array}$ & $\begin{array}{c}(4) \\
25 \% \\
\text { fee }\end{array}$ \\
\hline 1 & $\beta=1, \tilde{\beta}=1$ & $100.0 \%$ & $89.3 \%$ & $99.5 \%$ & $86.1 \%$ \\
\hline 2 & $\beta=0.74, \tilde{\beta}=0.77$ (primary estimates) & $88.8 \%$ & $80.4 \%$ & $92.8 \%$ & $74.6 \%$ \\
\hline 3 & $\beta=0.74, \tilde{\beta}=0.77$, consume in $t=0$ & $86.0 \%$ & $78.9 \%$ & $90.5 \%$ & $70.4 \%$ \\
\hline 4 & Heterogeneous & $76.3 \%$ & $69.7 \%$ & $92.5 \%$ & $61.7 \%$ \\
\hline 5 & $\beta=0.74, \tilde{\beta}=1$ & $75.2 \%$ & $69.6 \%$ & $91.9 \%$ & $59.0 \%$ \\
\hline 6 & $\beta=0.74, \tilde{\beta}=0.74$ & $90.8 \%$ & $82.0 \%$ & $92.9 \%$ & $76.7 \%$ \\
\hline 7 & $\beta=0.74, \tilde{\beta_{0}}=0.88, \tilde{\beta_{1}}=0.74$ (learning) & $86.4 \%$ & $78.3 \%$ & $92.3 \%$ & $70.3 \%$ \\
\hline 8 & Primary, heterogeneous, learning, consume in $t=0$ & $70.9 \%$ & $68.1 \%$ & $88.0 \%$ & $50.1 \%$ \\
\hline 9 & $\beta=0.63, \tilde{\beta}=0.86$ (expert forecast) & $47.0 \%$ & $46.6 \%$ & $88.3 \%$ & $26.4 \%$ \\
\hline 10 & $\beta=0.63, \tilde{\beta}=0.86$, consume in $t=0$ & $32.2 \%$ & $38.8 \%$ & $82.8 \%$ & $1.7 \%$ \\
\hline
\end{tabular}

Notes: In each cell, we present welfare as a percent of the surplus that time-consistent borrowers derive from the availability of payday loans under a $\$ 500$ loan size cap. Panels (a) and (b) are calibrated assuming borrowers have higher and lower demand elasticities, respectively. Panel (a) assumes that $\alpha_{0}=0.002$. Panel (b) assumes that $\alpha_{0}=0.0002$. "Rollover restriction" in column 3 refers to the requirement that borrowers repay by period $t=3$ at the latest. " $25 \%$ fee" in column 4 refers to an increase in the borrowing fee from $15 \%$ to $25 \%$, which might be caused by substitution to higher-cost credit after a payday loan ban. Rows 3 and 8 present alternative analyses where the benefits of the loan accrue fully in $t=0$, so borrowers overborrow relative to the welfare criterion. Rows 4 and 8 model heterogeneity, where half the population is timeconsistent and the other half has $\beta$ and $\tilde{\beta}$ such that the population averages correspond to the assumptions in rows 2 and 7 , respectively. Row 7 models learning, assuming $\beta=0.74, \tilde{\beta}_{0}=0.88$ in periods $0 \leq t \leq 3$, and $\tilde{\beta}_{1}=\beta$ in periods $t \geq 4$. Rows 9 and 10 set $\beta$ and $\tilde{\beta}$ to match expert forecasts. 
Figure 1: Identification of Misprediction and Perceived Time Inconsistency

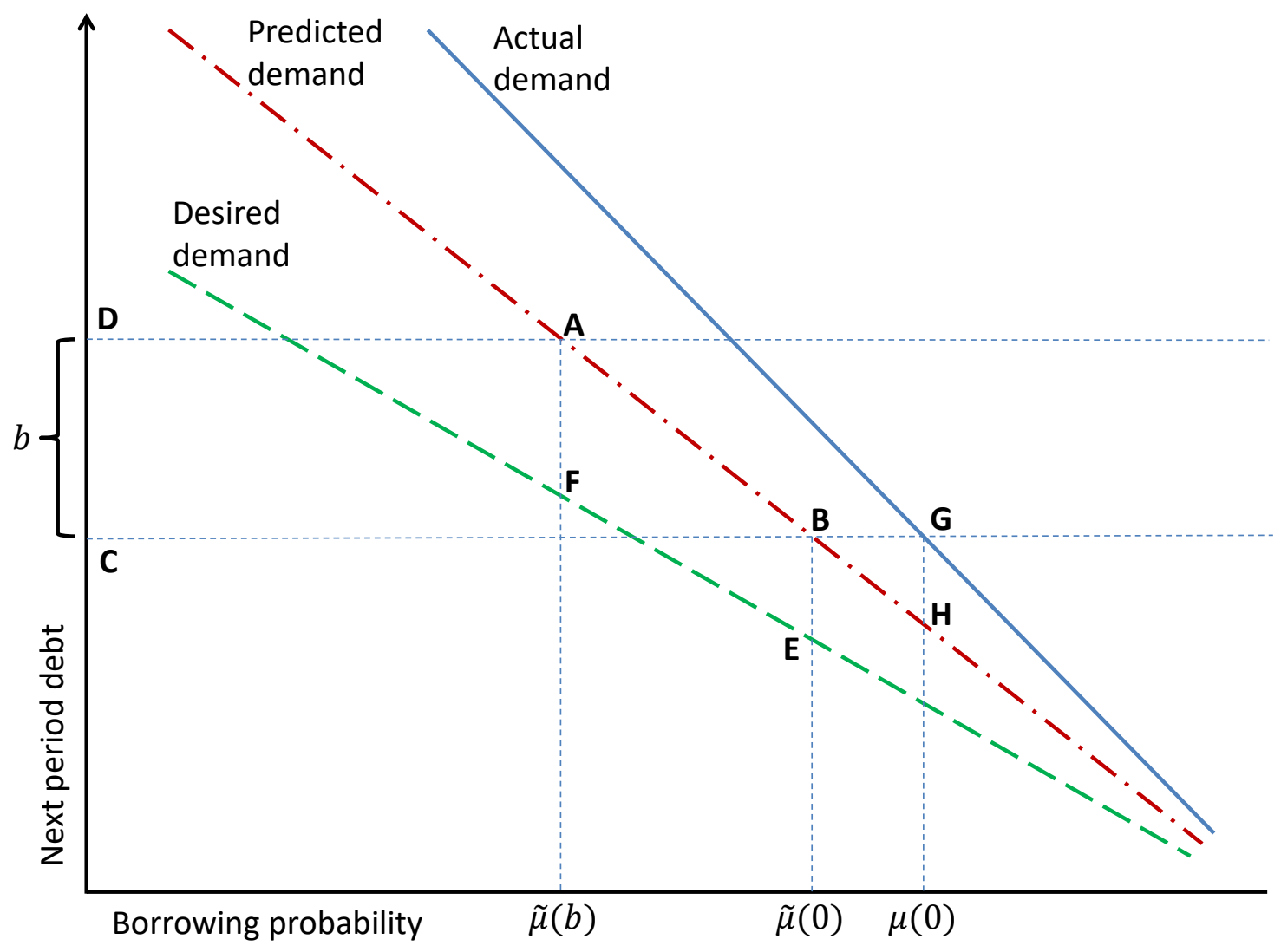

Notes: This figure illustrates our model of misprediction and time inconsistency assuming that the perceived continuation value is linear in debt owed. The y-axis plots the next period debt that results from borrowing. The x-axis plots the probability of borrowing given the distribution of unpredictable shocks. Predicted and desired demand are from the perspective of the previous period self. $b$ is the amount of the no-borrowing incentive, and $\mu(b)$ and $\tilde{\mu}(b)$ are the actual and predicted reborrowing probabilities.

In the present focus model, the period 1 self determines actual demand; that self discounts period 2 debt $\operatorname{cost} \tilde{C}$ by $\beta \delta$ relative to period 1 utility. The period 0 self predicts that the period 1 self will instead discount $\tilde{C}$ by $\tilde{\beta} \delta$. The period 0 self would prefer that the period 1 self discount $\tilde{C}$ by only $\delta$ instead of the predicted $\tilde{\beta} \delta$ relative to period 1 utility. Thus, the difference between actual and predicted demand is increasing in $\tilde{\beta}-\beta$, while the difference between predicted and desired demand is increasing in $1-\tilde{\beta}$. With linear demand curves and risk neutrality, the vertical difference between actual and predicted demand is a linear function of $\tilde{\beta}-\beta$, and the vertical difference between predicted and desired demand is a linear function of $1-\tilde{\beta}$. 


\section{Figure 2: Predicted and Actual Borrowing}

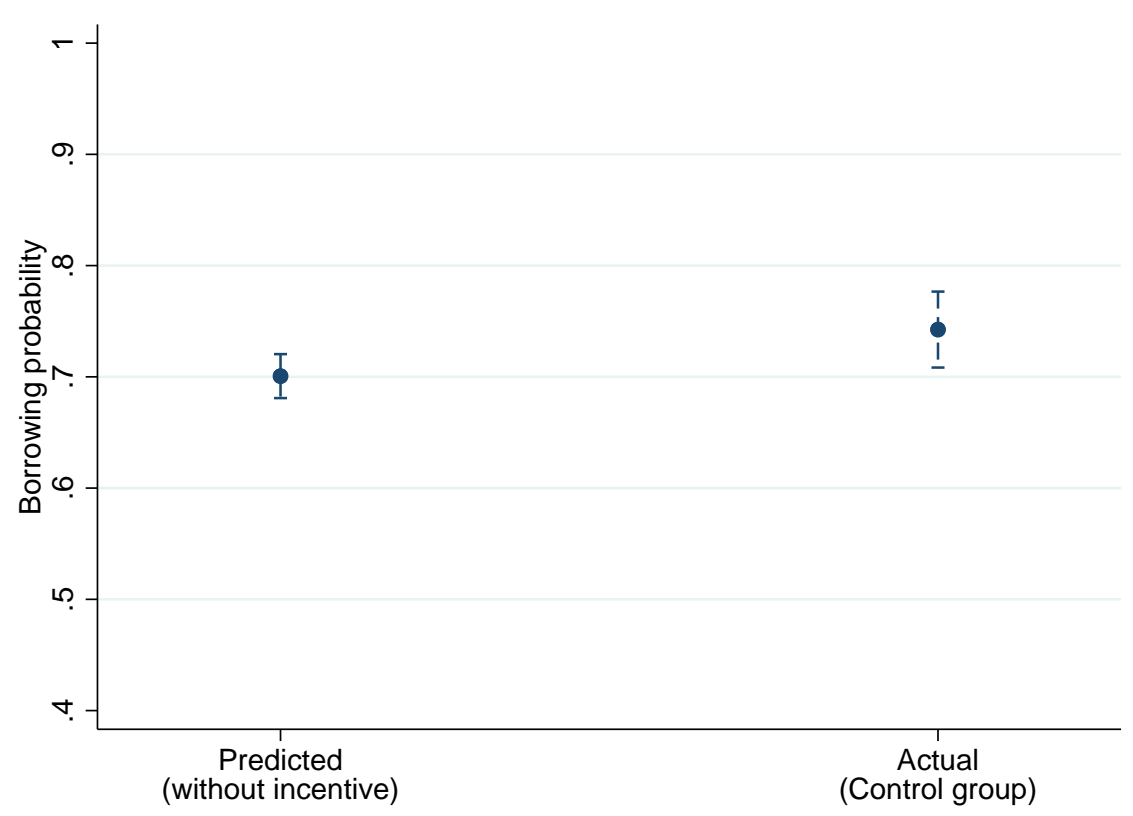

Notes: The left spike presents the average predicted probability of getting another payday loan in the next eight weeks without the no-borrowing incentive. The right spike presents the actual probability of getting another payday loan in the next eight weeks for the Control group, which did not receive the no-borrowing incentive. Error bars represent 95 percent confidence intervals. 


\section{Figure 3: Misprediction by Experience}

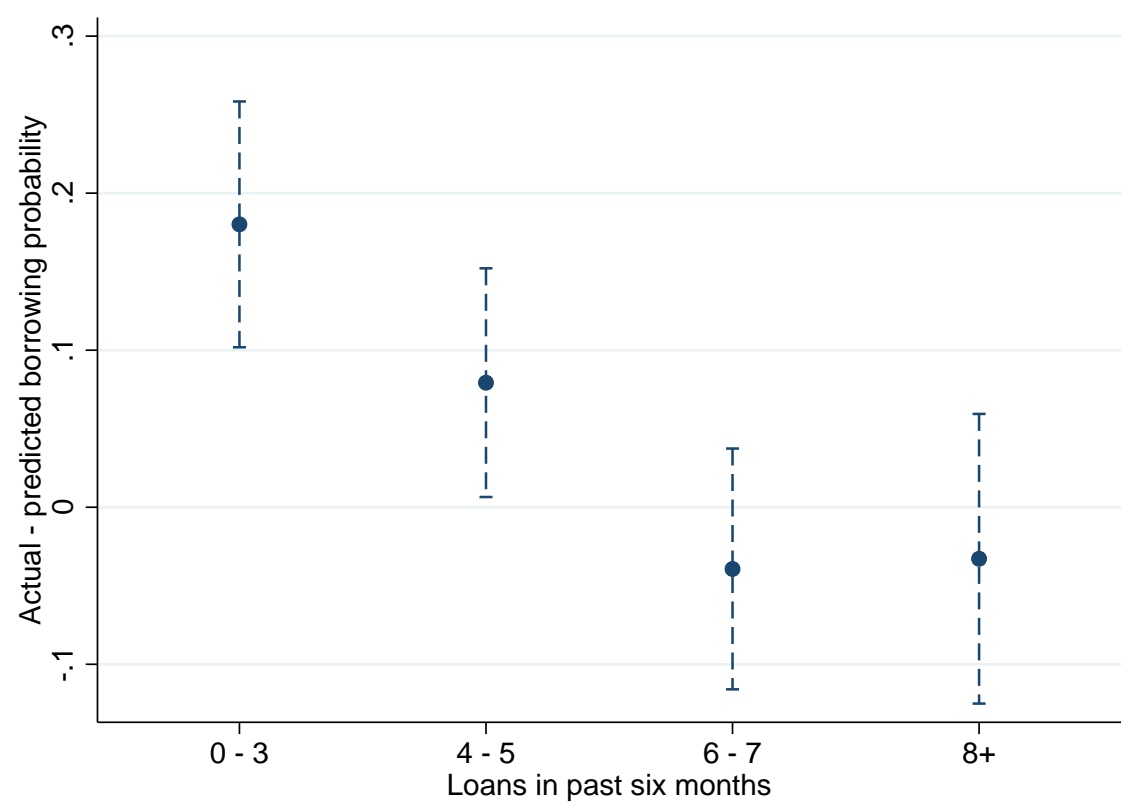

Notes: This figure presents the actual borrowing probability minus the average predicted borrowing probability within four subgroups defined by the number of loans taken out from the Lender in the six months before taking the survey. This figure includes only the Control group. Error bars represent 95 percent confidence intervals. 
Figure 4: Experts' Beliefs about Borrowers' Predicted Borrowing Probability

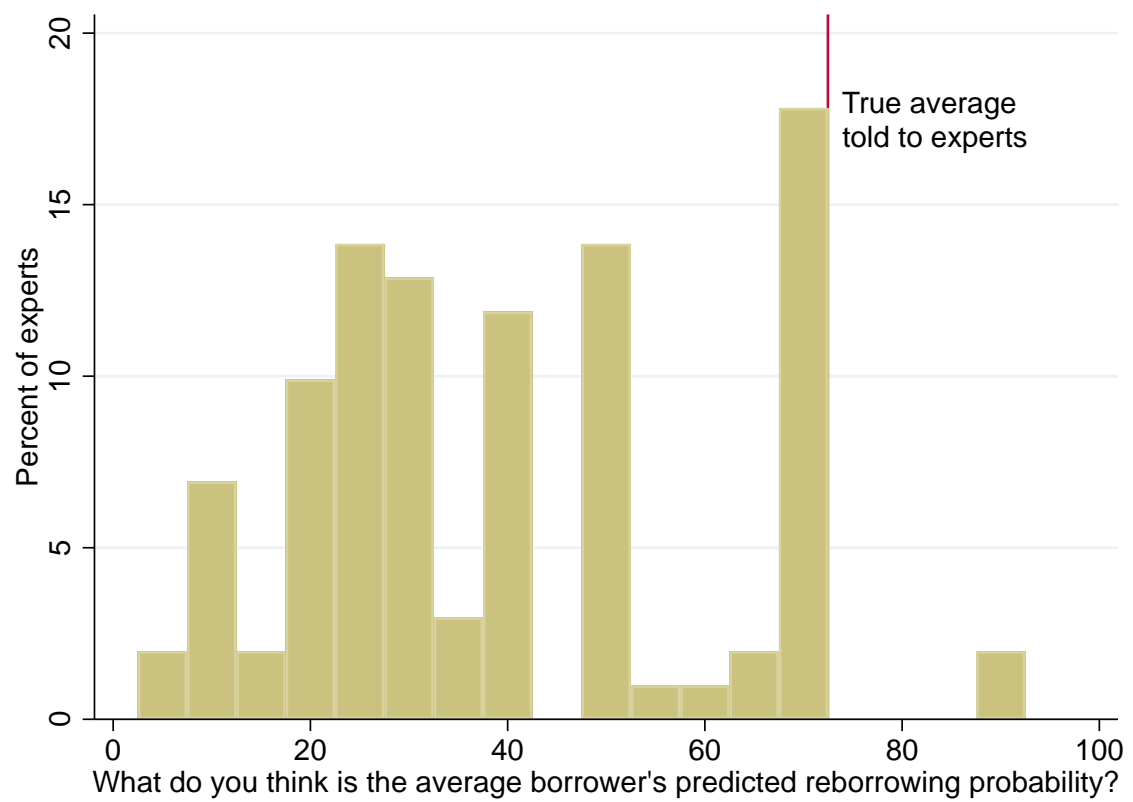

Notes: This is a histogram of experts' beliefs about the average borrower's predicted probability of borrowing again over the next eight weeks. Data are from our survey of expert opinion, which was administered before our paper was released. As a benchmark, we told experts that the true reborrowing probability was 70 percent, which was slightly lower than the Control group's actual average of 74 percent. 
Figure 5: Predicted and Actual Effects of No-Borrowing Incentive

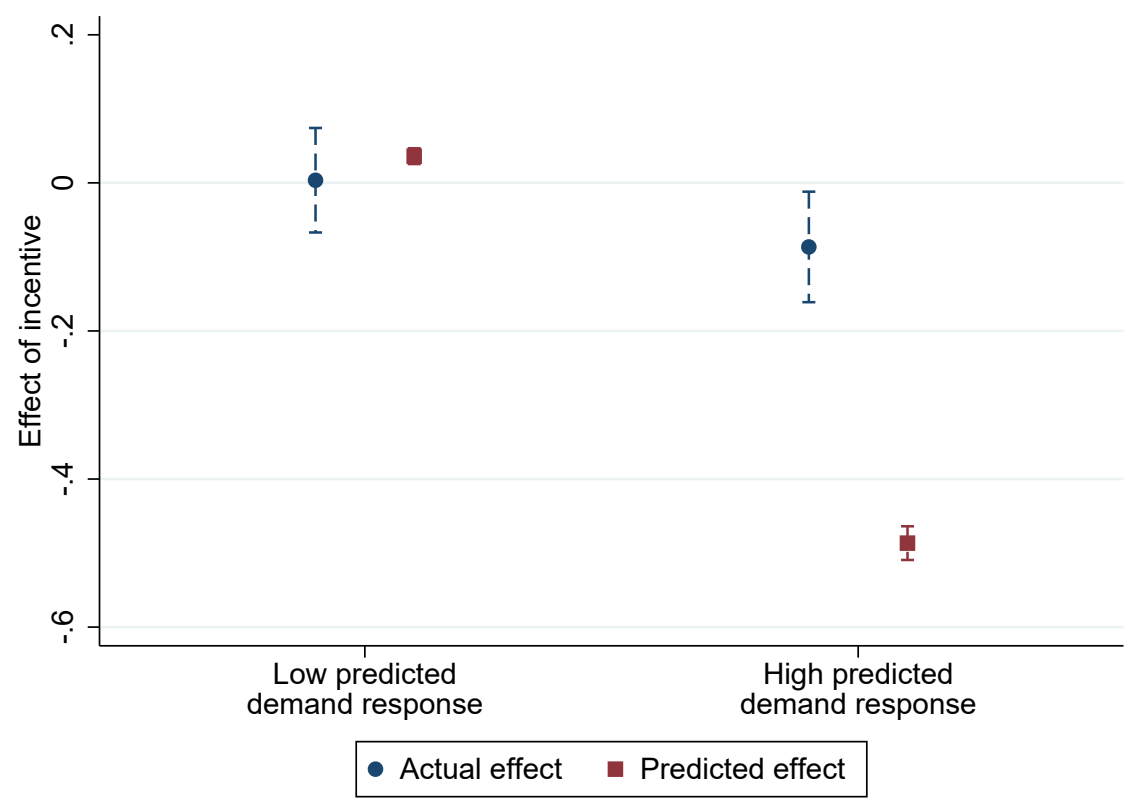

Notes: This figure presents the predicted and actual effects of the no-borrowing incentive on the probability of getting another loan in the next eight weeks after the survey. "High predicted demand response" includes people who reported that they would have a lower borrowing probability with the incentive compared to without. "Low predicted demand response" includes people who reported that they would have the same or higher borrowing probability with the incentive. About five percent of people reported that they would have a higher borrowing probability with the incentive; this is to be expected due to noise in survey responses. Error bars represent 95 percent confidence intervals. 


\section{Figure 6: Behavior Change Premium and Risk Aversion}

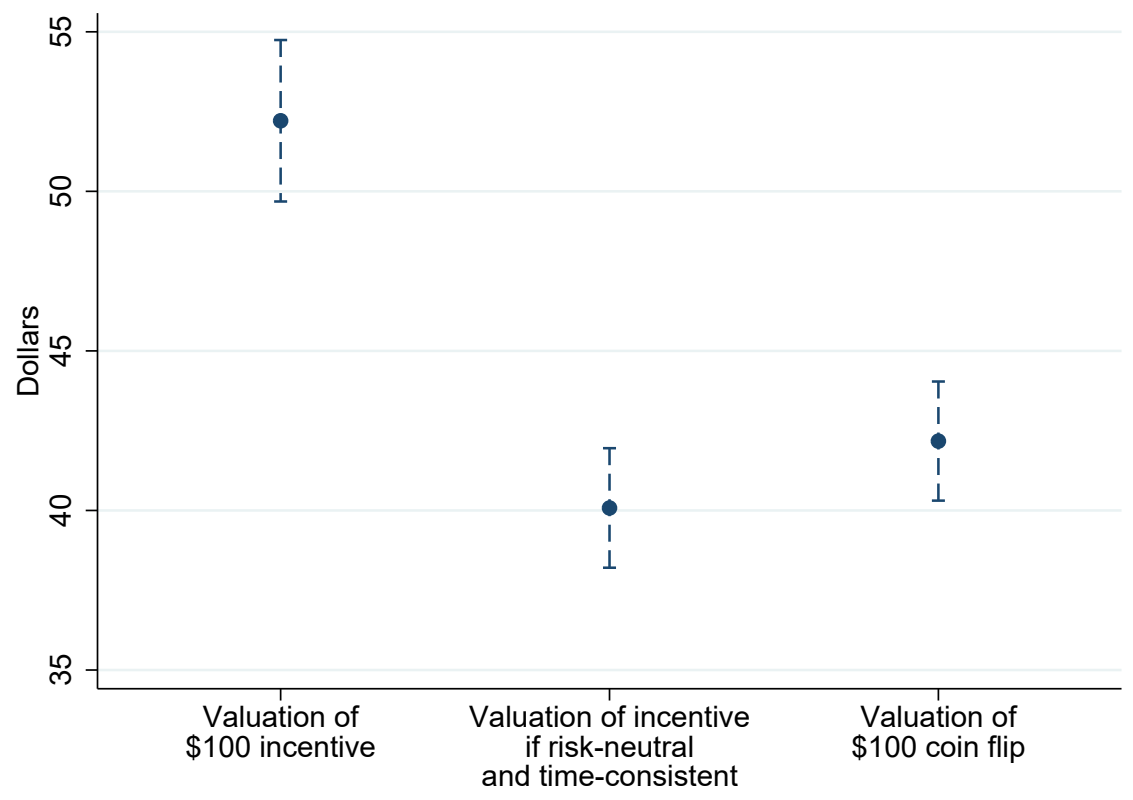

Notes: The first and third spikes are the average valuation of the $\$ 100$ no-borrowing incentive and the $\$ 100$ coin flip, respectively. The second spike is the average of $w^{*}(100)$, the modeled valuation for a risk-neutral and time-consistent borrower. Error bars represent 95 percent confidence intervals. 


\section{Figure 7: Responses to Qualitative Time Consistency Questions}

(a) Desire for Motivation

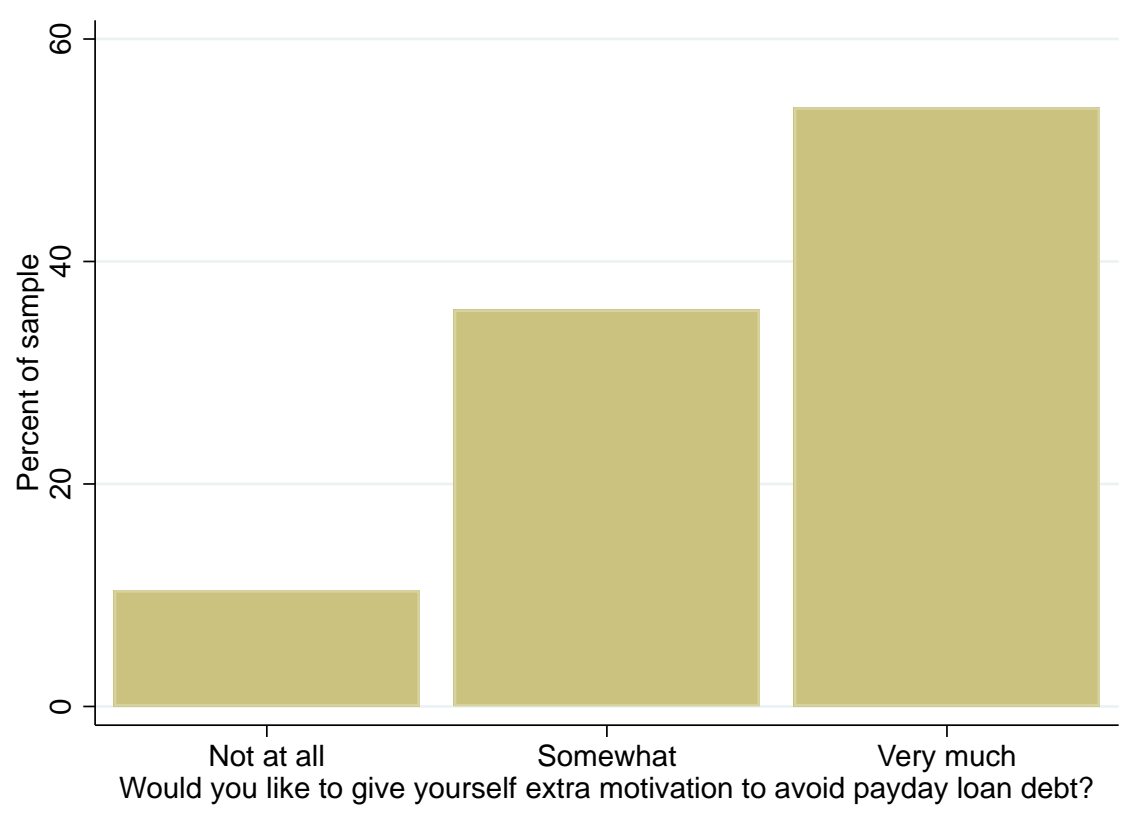

(b) Personal Impact of Rollover Restrictions

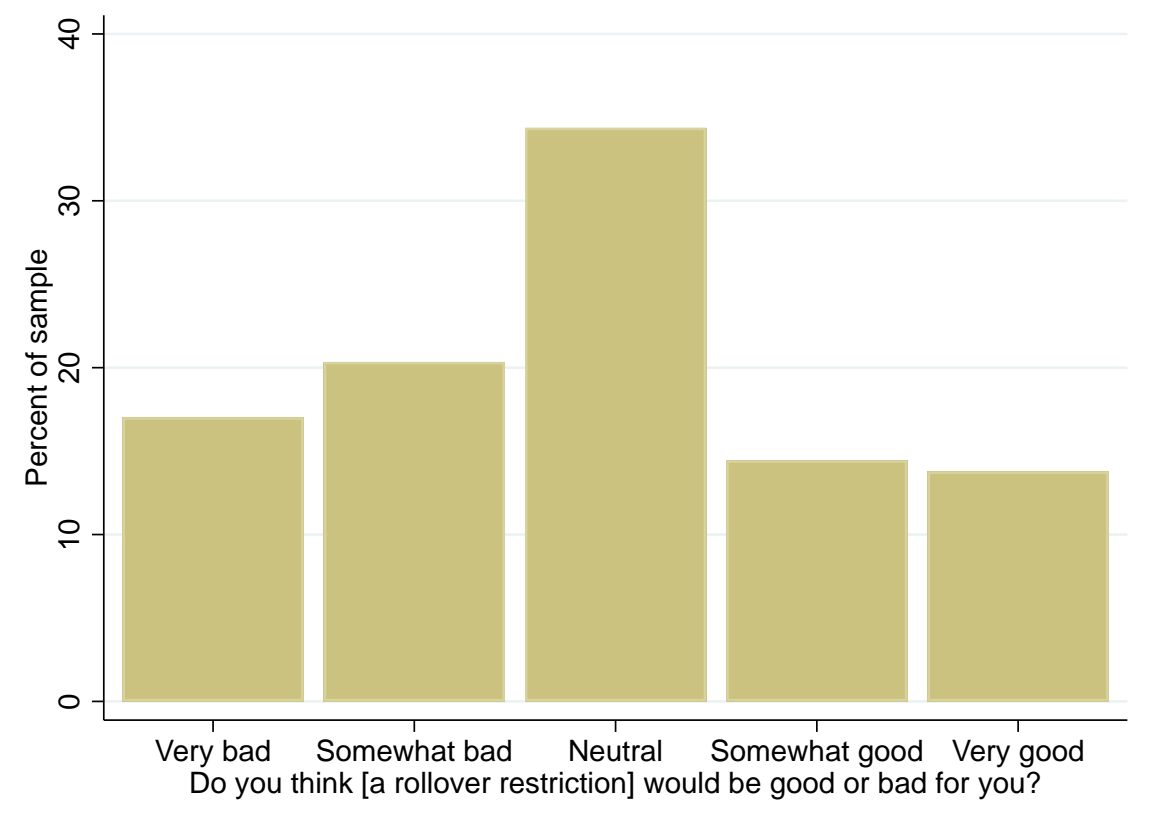

Notes: These are histograms of borrowers' responses to qualitative questions relatived to time consistency asked at the end of the survey. Panel (a) presents responses to the question, "To what extent would you like to give yourself extra motivation to avoid payday loan debt in the future?" Panel (b) presents responss to the question, "Some states have laws that prohibit people from taking out payday loans more than three paydays in a row. Do you think such a law would be good or bad for you?" 


\section{Figure 8: Heterogeneity in Behavior Change Premium by Survey Responses}

(a) Heterogeneity by Stated Desire for Motivation

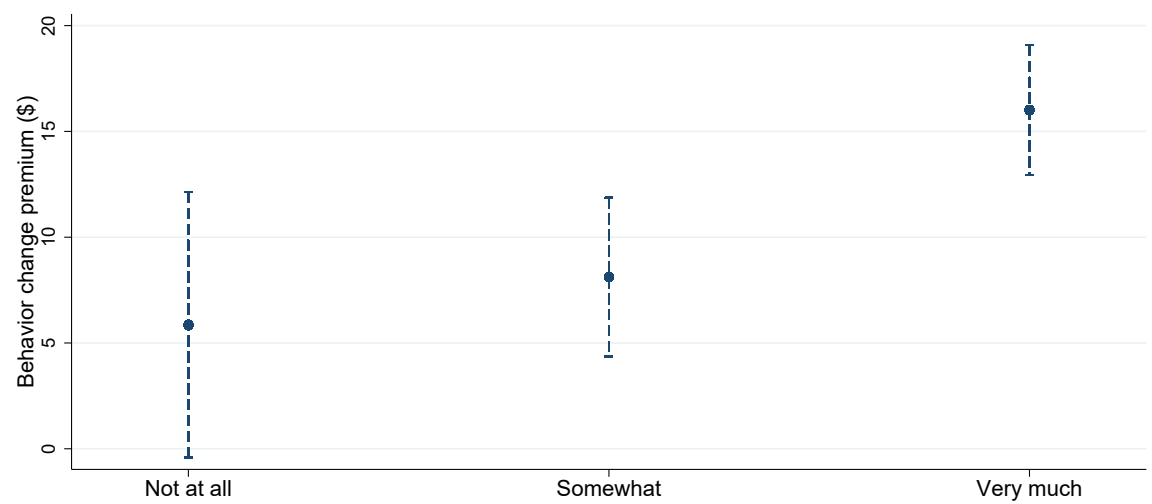

(b) Heterogeneity by Beliefs About Personal Impact of Rollover Restrictions

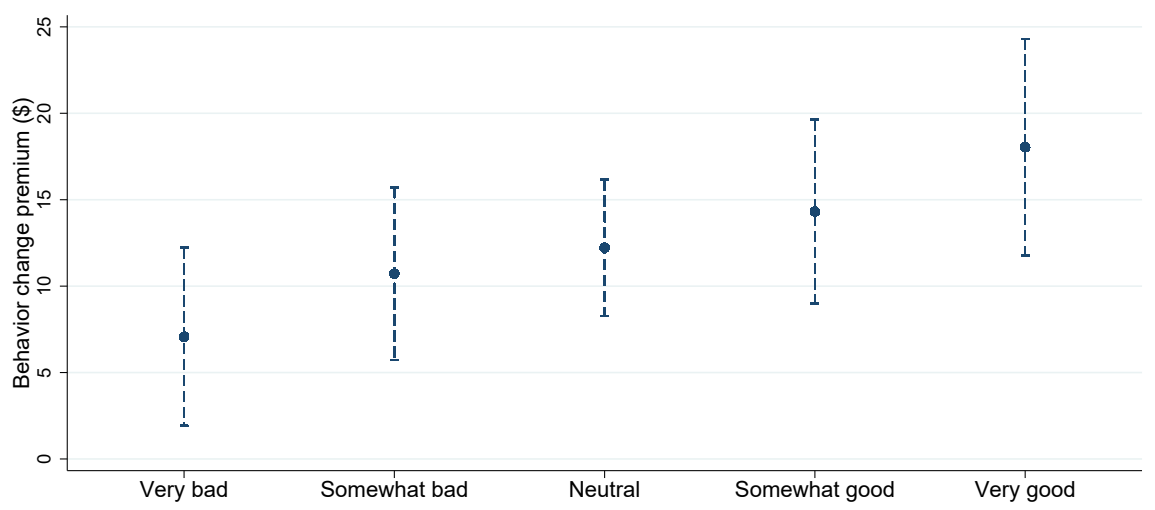

(c) Heterogeneity by Predicted Demand Response

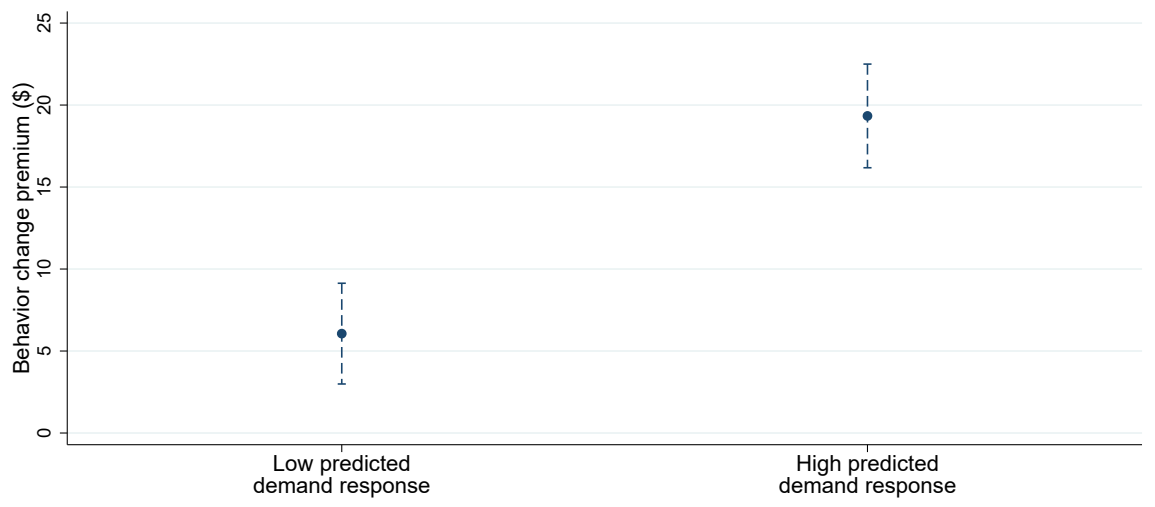

Notes: The behavior change premium equals $w(100)-w^{*}(100)$, the valuation of the $\$ 100$ no-borrowing incentive minus the modeled valuation for a risk-neutral and time-consistent borrower. Panel (a) presents heterogeneity by response to the question, "To what extent would you like to give yourself extra motivation to avoid payday loan debt in the future?" Panel (b) presents heterogeneity by response to the question, "Some states have laws that prohibit people from taking out payday loans more than three paydays in a row. Do you think such a law would be good or bad for you?" In Panel (c), "High predicted demand response" includes people who reported that they would have a lower borrowing probability with the incentive compared to without, and "Low predicted demand response" includes people who reported that they would have the same or higher borrowing probability with the incentive. Er.or bars represent 95 percent confidence intervals. 
Figure 9: Timing of Model

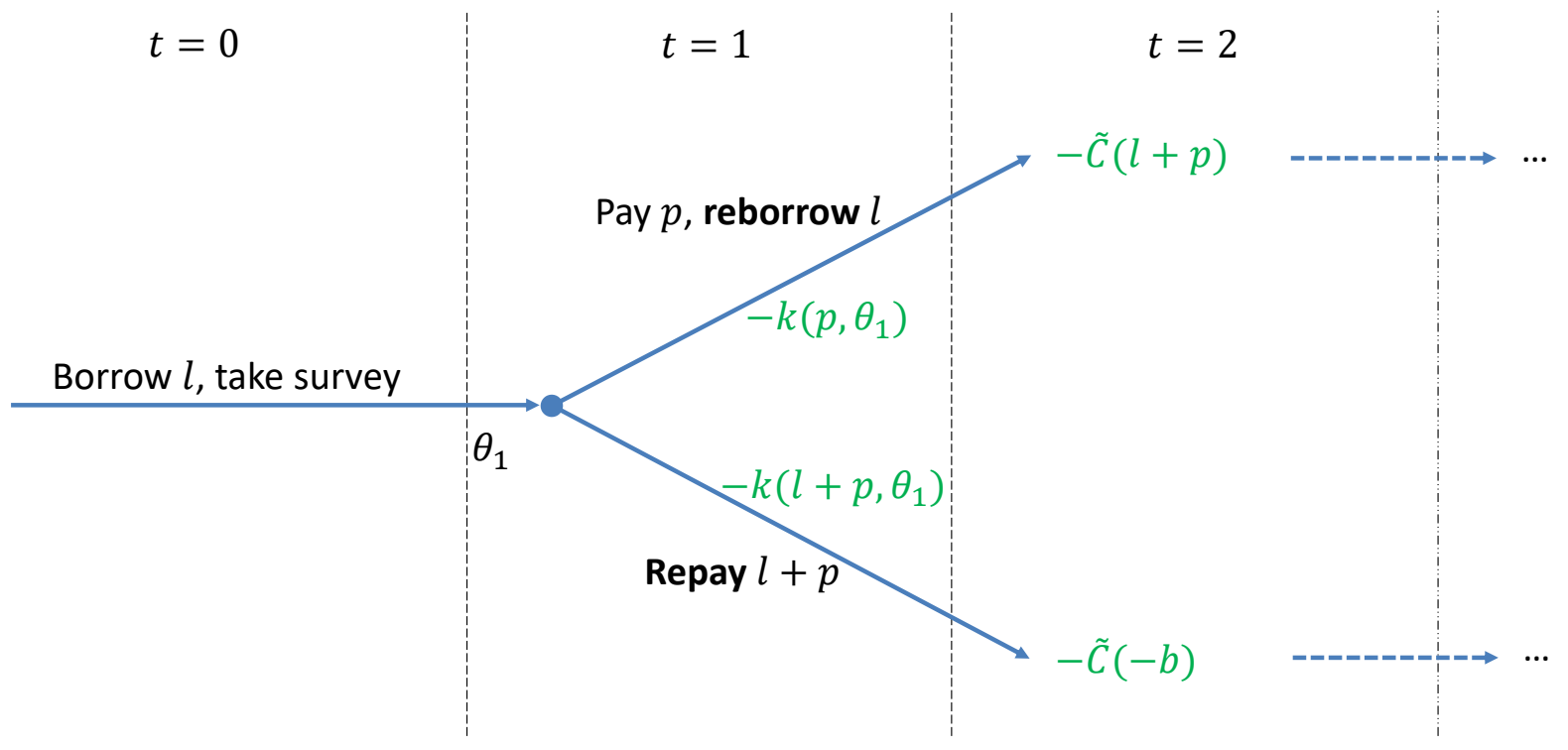

Notes: This figure illustrates the timing of the model used for estimation in Section 7 . We focus on three periods of a potentially longer or infinite-horizon model. In period 0 , the borrower gets a loan of amount $l$ and then takes our survey. The next eight weeks after the survey are period 1 . At the beginning of period 1 , the borrower receives a smoothly distributed transitory repayment cost shock $\theta$. In period 1 , the borrower chooses to either repay or reborrow. If she repays, she pays the principal and fee $l+p(l)$ in period 1 and receives no-borrowing incentive $b$ in period 2 . If she reborrows, she pays only the fee $p(l)$ in period 1 , owes $l+p(l)$ in period 2, and does not receive the no-borrowing incentive. The cost of repaying amount $x$ in period 1 is $k(x, \theta) . \tilde{C}(x)$ is the cost of period 2 debt: specifically, the reduction in period 2 continuation value (as perceived before period 2) from starting period 2 with debt $x$. 
Figure 10: Experts' Beliefs about Borrowers' Perceived Present Focus

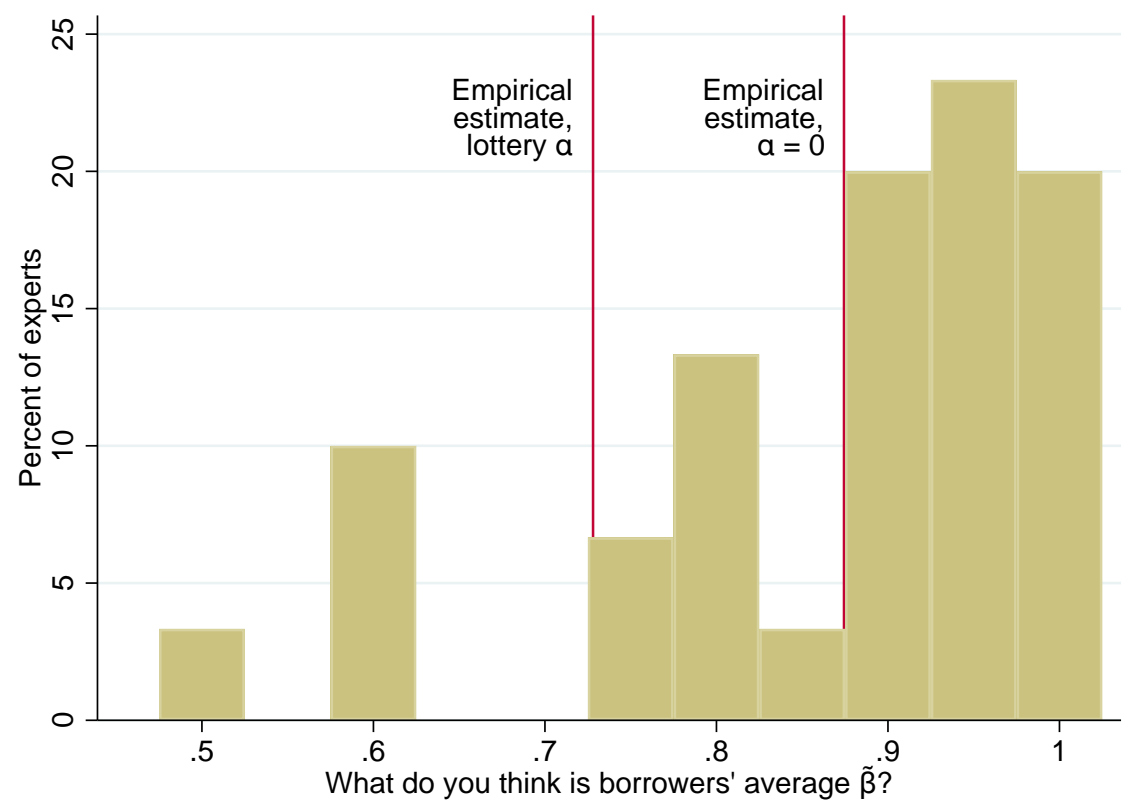

Notes: This is a histogram of experts' predictions of the average borrower's perceived present focus parameter $\tilde{\beta}$; this question was only asked of experts who reported that they had a PhD in economics. Data are from our survey of expert opinion, which was administered before our paper was released. 


\section{Figure 11: Experts' Beliefs about Payday Loan Regulation}
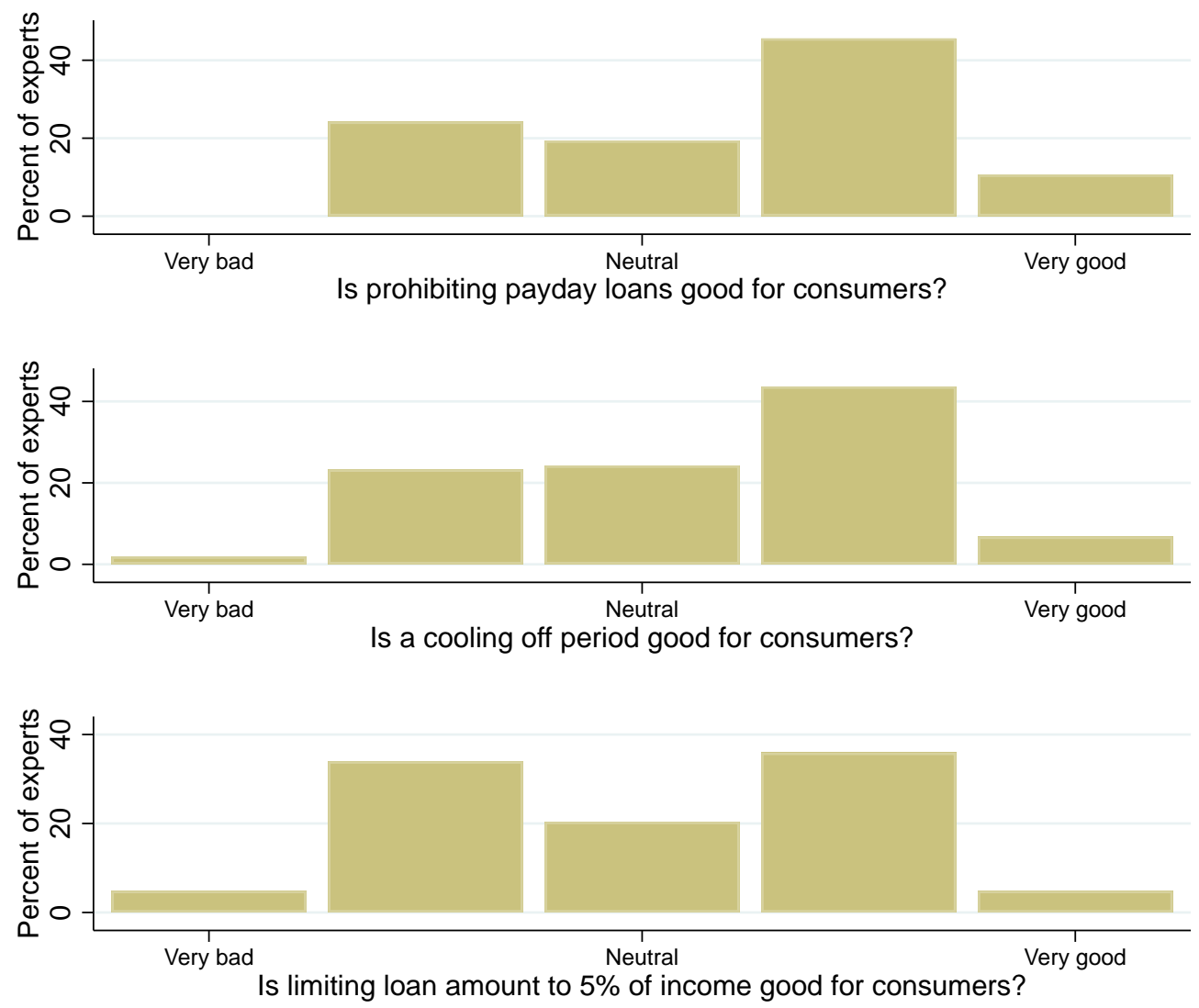

Notes: These are histograms of experts' beliefs about whether specific payday loan regulations are good or bad for consumers overall. Data are from our survey of expert opinion, which was administered before our paper was released. 


\section{Figure 12: Welfare Effects of Payday Loan Regulation}

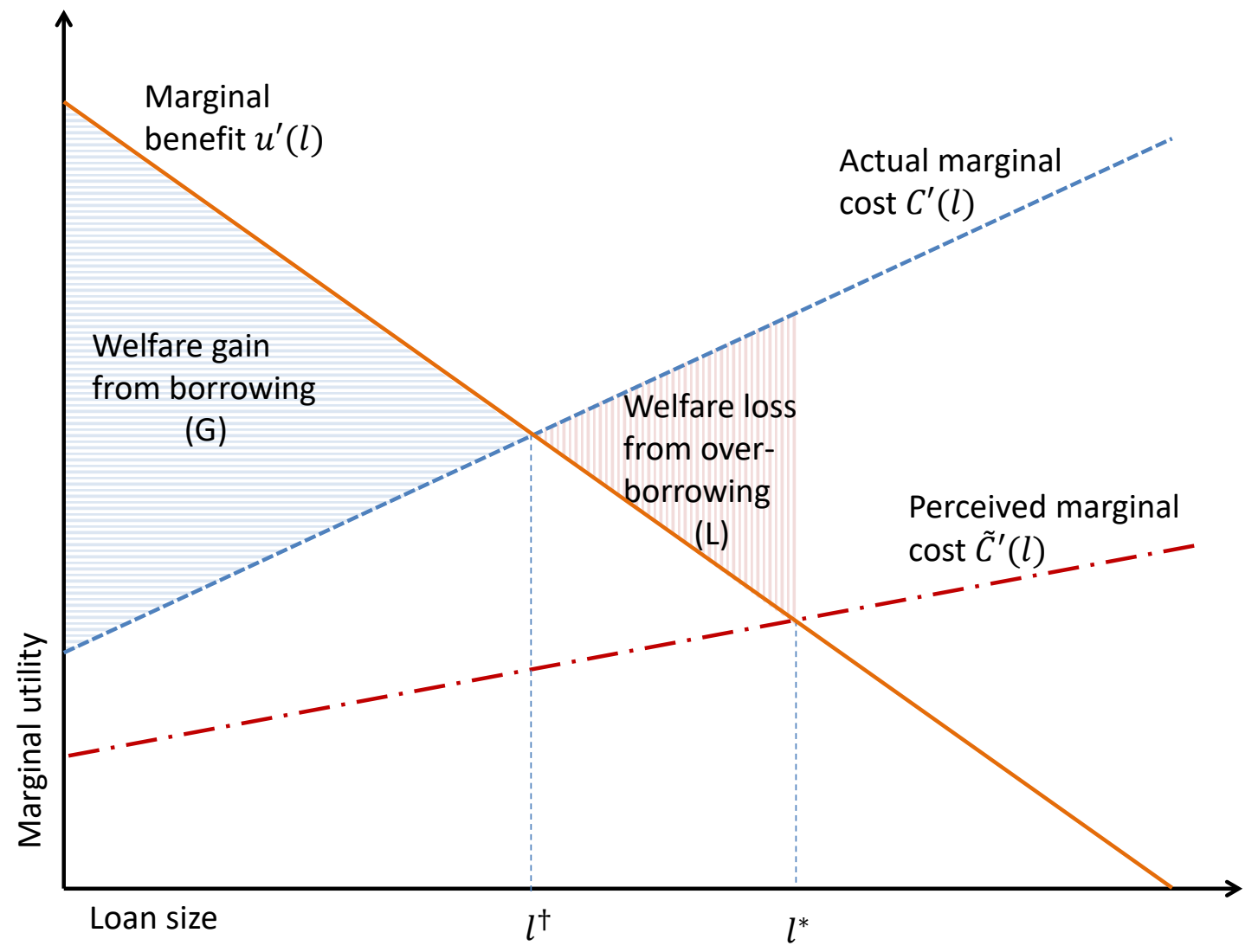

Notes: This figure illustrates loan size choice and resulting borrower welfare. $u^{\prime}(l)$ is the marginal utility benefit from borrowing an additional dollar. $C^{\prime}(l)$ and $\tilde{C}^{\prime}(l)$ are the actual and perceived marginal costs of repaying (or defaulting on) an additional dollar starting in period 1 , discounted to period 1 using the period 0 self's discount function. Optimizing borrowers would choose $l$ to equate marginal benefit $u^{\prime}(l)$ and actual expected marginal repayment cost $C^{\prime}(l)$, giving loan size $l^{\dagger}$. The resulting welfare gain is the triangle $G$. Borrowers who misperceive repayment costs choose $l$ to equate $u^{\prime}(l)$ and perceived marginal repayment cost $\tilde{C}^{\prime}(l)$, giving loan size $l^{*}$ that exceeds the optimum $l^{\dagger}$. The resulting welfare loss from overborrowing is the triangle $L$. 